1. EDT 603912
Document Control Services
2. To: (Receiving Organization)
3. From: (Originating Organization) Baseline Development and Management Systems

6. Cog. Engr.:

John M. Vann
5. Proj./Prog./Dept./Div.:

Tank Waste Remediation

Systems (TWRS)

8. Originator Remarks:

This plan describes the configuration management program for Tank Waste Remediation System (TWRS) and defines the configuration management program.

11. Receiver Remarks: requirements and responsibilities for execution of the TwRS

4. Related EDT No.

N/A

7. Purchase Order No.:

N/A

9. Equip. / Component No.

$\mathrm{N} / \mathrm{A}$

10. System/Bldg./Facility:

$\mathrm{N} / \mathrm{A}$

12. Major Assm. Dwg. No.:

N/A

13. Permit/Permit Application No.:

$\mathrm{N} / \mathrm{A}$

14. Required Response Date: 4/30/96

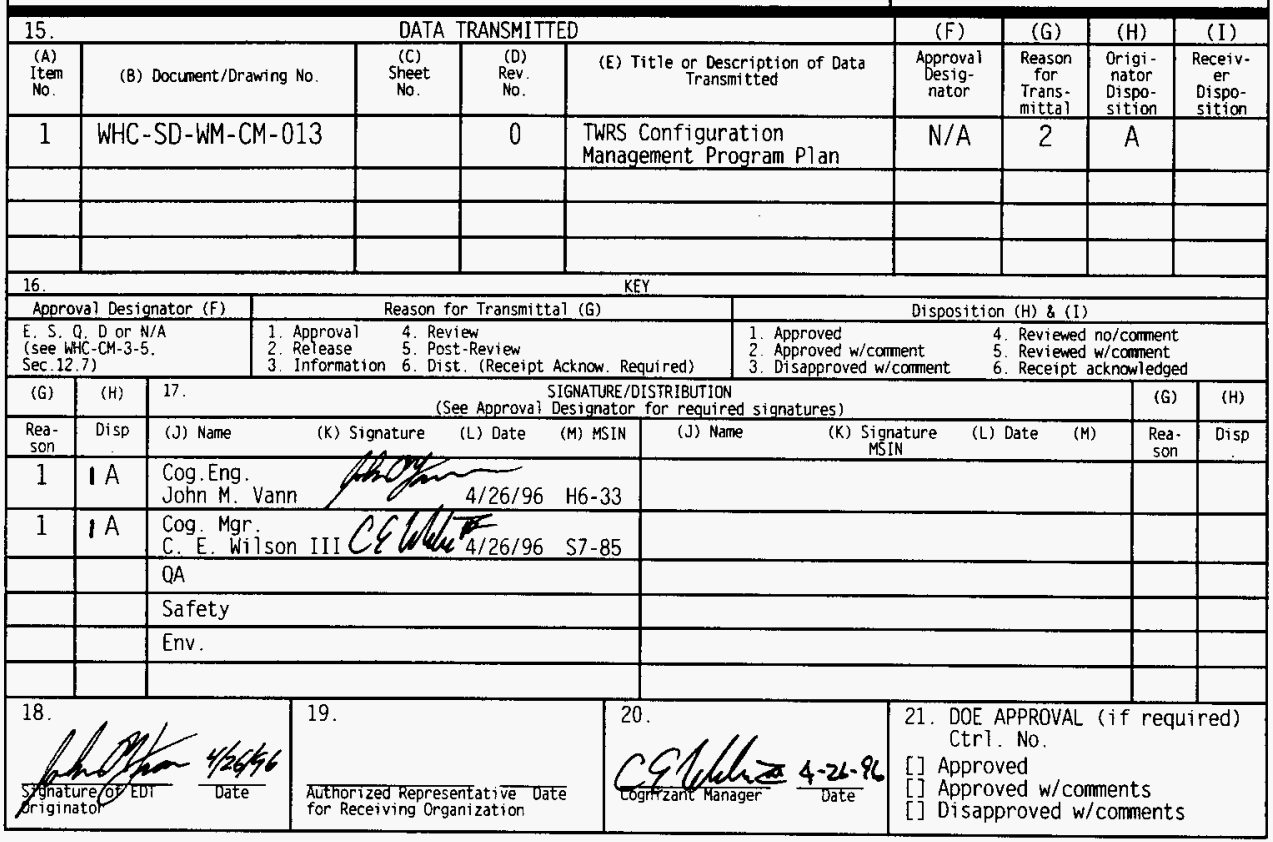

BD-7400-172-2 (04/94) GEF097 


\section{TWRS Configuration Management Program Plan}

\section{J.M. Vann}

Westinghouse Hanford Company, Richland, WA 99352

U.S. Department of Energy Contract DE-AC06-87RL10930

EDT/ECN: 603912

Org Code: 72230

B\&R Code: EW3120075
UC: 620

Charge Code: D1N24

Total Pages: 69

Key Words: TWRS, CM. CMPP. Configuration. Management, Program, Plan. CMIP. Technical, Baseline, Integrated, Configuration, Document, Change. Control

Abstract: The TWRS Configuration Management Program Plan (CMPP) integrates technical and administrative controls to establish and maintain consistency among requirements, product configuration, and product information for TWRS products during all life cycle phases. This CMPP wi11 be used by TWRS management and configuration management personnel to establish and manage the technical and integrated baselines and controls and status changes to those baselines.

TRADEMARK DISCLAIMER. Reference herein to any specific comercial product. process, or service by trade name, trademark. manufacturer. or otherwise. does not necessarily constitute or imply its endorsement. recommendation. or favoring by the United States Government or any agency thereof or its contractors or subcontractors.

Printed in the United States of America. To obtain copies of this document, contact: WHC/BCS Document Control Services, P.O. Box 1970. Mailstop H6-08, Richland WA 99352, Phone (509) 372-2420: Fax (509) 376-4989
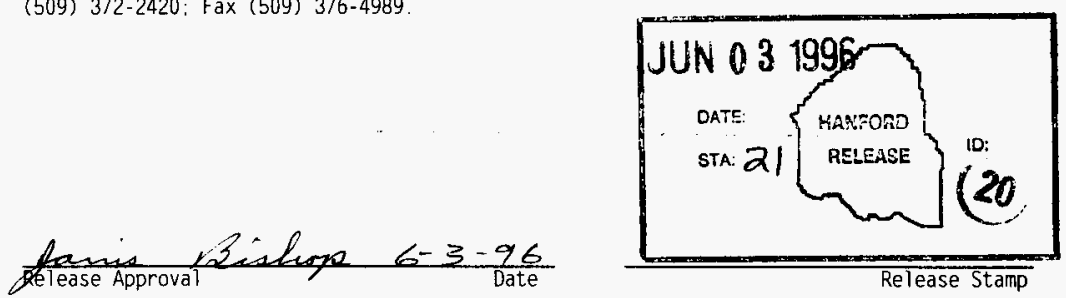

\section{Approved for Public Release}




\section{TANK WASTE REMEDIATION SYSTEM}

\section{CONFIGURATION MANAGEMENT PROGRAM PLAN}

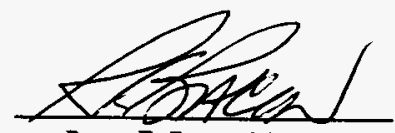

Roger F. Bacon, Manager

Tank Waste Remediation System 
WHC-SD-WM-CM-013

Rev 0

This page intentionally left blank. 
TABLE OF CONTENTS

EXECUTIVE SUMMARY $\quad v$

1.0 INTRODUCTION 1

1.1 Purpose 1

1.2 Scope 2

1.3 Objective 2

2.0 CONFIGURATION MANAGEMENT PROGRAM MANAGEMENT 5

2.1 Program Planning 5

2.2 Configuration Management Training 5

2.3 Vendor and Contractor Control 6

$\begin{array}{lll}2.4 & \text { Interfaces } & 7\end{array}$

2.5 Procedures 7

$\begin{array}{lll}2.6 & \text { Data Management } & 8\end{array}$

$3.0 \quad$ ROLES AND RESPONSIBILITIES 11

$3.1 \quad$ U.S. Department of Energy . 11

3.2 Management and Operating Contractor 11

3.3 Systems Integration 11

3.4 WHC/ICF KH Site Engineer 12

3.5 Tank Waste Remediation System 12

3.6 Emergency, Safety, and Quality Services 12

3.7 BCS Richland (BCSR) 12

$\begin{array}{lll}3.8 & \text { Other Participants } & 12\end{array}$

4.0 CONFIGURATION ITEM SCOPE CRITERIA 13

$\begin{array}{lll}4.1 & \text { Program Scope } & 13\end{array}$

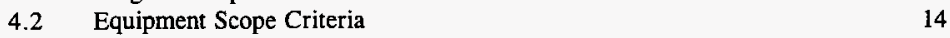

5.0 BASELINE MANAGEMENT 17

5.1 Technical, Schedule, and Cost Integration 17

$\begin{array}{lll}5.2 & \text { Technical Control } & 18\end{array}$

$\begin{array}{lll}5.3 & \text { Schedule Control } & 22\end{array}$

$\begin{array}{lll}5.4 & \text { Cost Control } & 23 \\ 5.5 & 23\end{array}$

$\begin{array}{lll}5.5 & \text { Product Information Control } & 23\end{array}$

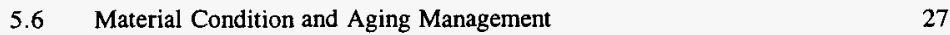

$\begin{array}{lll}5.7 & \text { Design Reconstitution } & 27\end{array}$

6.0 CHANGE CONTROL $\quad 29$

$\begin{array}{lll}6.1 & \text { Change Mechanisms } & 29\end{array}$

6.2 Identification and Documentation of Changes 30

6.3 Change Control Processes 31

6.4 Change Control Tracking 36 
TABLE OF CONTENTS (cont.)

$\begin{array}{lll}7.0 & \text { CONFIGURATION STATUS ACCOUNTING } & 37\end{array}$

8.0 CONFIGURATION MANAGEMENT PROGRAM ASSESSMENTS 39

8.1 Programmatic Assessments 39

8.2 Functional Configuration Assessments 40

$\begin{array}{lll}\text { 8.3 Physical Configuration Assessment } & 41\end{array}$

8.4 Product Performance Monitoring 41

8.5 Post-Modification Testing 41

$\begin{array}{lll}9.0 & \text { REFERENCES } & 43\end{array}$

$\begin{array}{lll}10.0 & \text { BIBLIOGRAPHY } & 45\end{array}$

$\begin{array}{lll}11.0 & \text { GLOSSARY } & 47\end{array}$

$\begin{array}{lll}12.0 & \text { ACRONYMS } & 53\end{array}$

\section{FIGURES}

Figure 1 - TWRS Integrated Baseline Document Hierarchy vi

Figure 2 - Configuration Management Program Life Cycle $\quad 2$

Figure 3 - Technical, Schedule, and Cost Integration $\quad 17$

Figure 4 - Typical Change Control Process $\quad 32$

\section{TABLES}

Table 1 - Document Source/Location $\quad$. $\quad 26$

Table 2 - Change Status Locations $\quad 36$

Table 3 - Technical Baseline Design Reviews 40

\section{APPENDIXES}

Appendix A - TWRS Work Breakdown Structure $\quad$ A-1 Appendix B - Graded Approach B-1 


\section{EXECUTIVE SUMMARY}

The TWRS Configuration Management Program Plan (CMPP) was developed to codify existing requirements and practices. The position that the TWRS CMPP plays in the TWRS document hierarchy is shown in Figure 1. This CMPP and the Configuration Management (CM) Implementation Plan implement the TWRS configuration management policy defined in DOE/RL-93-0106, "Tank Waste Remediation System, Program Management System Description," Annex 4, "Configuration Management Policy." Implementation of this CMPP ensures compliance with configuration management aspects in 10 CFR 830.120, "Quality Assurance Requirements."

The TWRS CMPP provides information considered to be effective as a summary in Paragraphs 1.0 and 2.0. Paragraph 3.0 contains general organization responsibilities for the implementation and maintenance of the TWRS configuration management program. The balance of this plan contains details for program implementation and application and performance of configuration management related activities.

A companion document (WHC-SD-WM-CM-014, "TWRS CM Program Implementation Plan") is being developed that will delineate responsible organizations, the actions they will take to satisfy configuration management criteria, and implementation dates for those actions. The implementation plan will be developed in conjunction with TWRS departments/groups. Upon issuance of this TWRS CMPP, department organizations will be expected to identify actions in progress for which they can take credit and additional program activities that should be included in the implementation plan. Future revisions are planned annually or as required to maintain this CMPP as a functional document.

Appendix A of this TWRS CMPP contains a Work Breakdown Structure (WBS) for the implementation of this program. Each TWRS department is expected to include only those WBS elements in its department WBS that are necessary for it to implement and maintain its configuration management responsibilities. This will allow integration of the necessary implementing tasks with the established configuration management WBS.

A systems engineering approach was used to develop this CMPP and its technical basis. The functions identified in the WBS are the flow-down from the need to have configuration management in support of the TWRS baseline. 
Figure 1. TWRS Integrated Baseline Document Hierarchy.

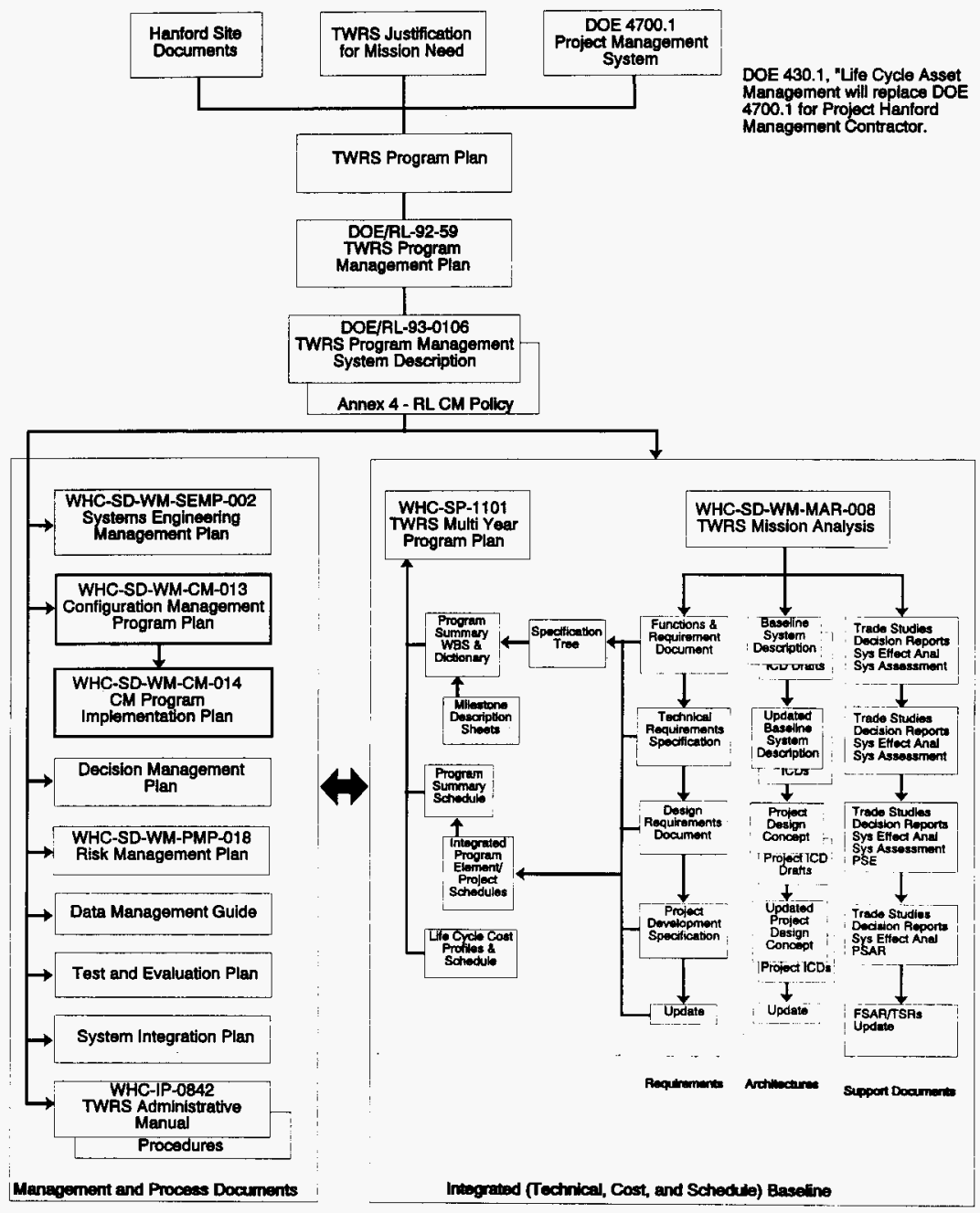




\subsection{INTRODUCTION}

This plan describes the configuration management program for Tank Waste Remediation System (TWRS) and defines the requirements and responsibilities for execution of the TWRS configuration management program. This Configuration Management Program Plan (CMPP) provides the methodology to establish, upgrade, reconstitute, and maintain consistency among the requirements, product configuration, and product information.

The technical consistency afforded by this program plan provides for the safe, economic, and environmentally sound management of TWRS products throughout their life cycles. This is necessary to achieve the mission objectives and support the DOE Integrated Site Baseline.

The TWRS CMPP complies with Westinghouse Hanford Company (WHC) configuration management requirements and aligns with the criteria established in the DOE Standard, DOE-STD-1073-93, "Guide to Operational Configuration Management," and DOE 4700.1, "Project Management System." This CMPP and the CM Implementation Plan (see Executive Summary) implement the TWRS configuration management policy defined in DOE/RL-93-0106, "Tank Waste Remediation System, Program Management System Description," Annex 4, "Configuration Management Policy." Implementation of this plan ensures compliance with the configuration management aspects of 10 CFR 830.120, "Quality Assurance Requirements."

The TWRS configuration management program also implements requirements of the Hanford Strategic Plan (October, 1994); RLID 5000.1, "Baseline Execution and Management Process;" WHC-SD-WM-SEMP-002, "Tank Waste Remediation System, Systems Engineering Management Plan;" and WHC-SD-WM-SRID-001, "High Level Waste Storage Tank Farms/242A Evaporator Standards/Requirements Identification Document;" and complies with the requirements established in applicable DOE Orders and Directives.

\subsection{PURPOSE}

The TWRS CMPP integrates technical and administrative controls to establish and maintain consistency among requirements, product configuration, and product information for TWRS products during all phases of the product's life cycle (see Figure 2). This CMPP will be used by TWRS management and configuration management personnel to establish and manage the technical and integrated baselines and controls and status changes to those baselines. This integrated baseline control ensures that selected products, schedules, and costs meet design, performance, customerdirected, and operational requirements. This includes ensuring that the Operational Baseline and operating configuration is maintained traceable to and in compliance with the Authorization Basis.

Actions in suppert of the baseline ensure that selected-products are-tested and used in accordance with their design basis and interface both physically and functionally. Controls ensure existing products and new modifications achieve safety, reliability, total quality and environmentallysound and cost-effective operation within the established schedule. 
Figure 2. Configuration Management Program Life Cycle.

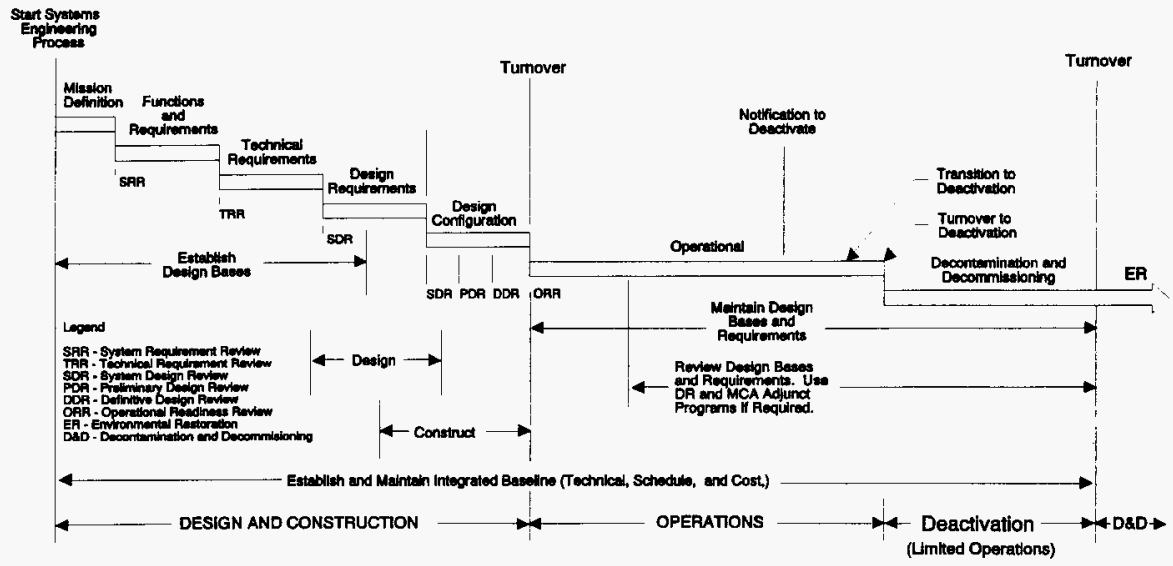

\section{$1.2 \quad$ SCOPE}

The TWRS CMPP applies to selected products and product information during all phases of the product life cycle within TWRS. The TWRS configuration management program is integrated with the engineering, operational, and administrative process of TWRS Systems Engineering Management Plan (SEMP) (WHC-SD-WM-SEMP-002). This configuration management program is integrated with the processes defined in WHC-CM-6-1, Standard Engineering Practices; the cost and schedule control processes defined in WHC-CM-2-5, Management Control System; the operational requirements of WHC-CM-1-8, Work Management; and the implementation of the technical baseline established through the systems engineering process.

\subsection{OBJECTIVE}

The efficient application of configuration management-uses a-graded-approach relying as much as possible on existing programs, processes, and implementing procedures. This CMPP delineates the configuration management program with the following objectives:

- Configuration Management Program Management - Provide for configuration management program integration among participants to ensure the integrity and quality of the integrated TWRS baseline, products, and product information and compliance with the Integrated Site Baseline. Provide for maintenance and continual improvement of configuration management processes. 
- Configuration Item Scope Criteria - Provide for consistent approach in selection of items subject to configuration management. Provide configuration item scope criteria and structure, system, and component (SSC) grading criteria.

- Integrated Baseline Control - Establish consistency and integration of the processes used for control of the technical, schedule, and cost components of an integrated baseline. Apply configuration management principles to establish and maintain consistency and traceability among requirements, bases (includes Authorization Basis), and functional and physical products (e.g., SSCs). Establish the controls to maintain the Operational Baseline traceable to and in compliance with the Authorization Basis.

- Control of Changes - Establish the process to be used by TWRS for changing the integrated baseline and products. Control and status changes to ensure the continued integrity and relationships among the requirements, product configuration, and product information.

- Configuration Status - Identify the process and procedures to be used for reporting current product configuration, including change activity and products that depart from specified requirements (e.g., deviations and waivers).

- Configuration Management Program Assessment - Provide the process to evaluate the effectiveness of the configuration management program, functional and physical capability of products, and testing. 
WHC-SD-WM-CM-013

Rev 0

This page intentionally left blank. 


\subsection{CONFIGURATION MANAGEMENT PROGRAM MANAGEMENT}

The program management element directs and monitors the development and implementation of the overall configuration management program. It establishes the criteria for the scope of the program; defines baselines, concepts, and terminology; identifies and controls configuration management organizational and programmatic interfaces; establishes the policy and criteria for required databases; and develops and maintains configuration management procedures. The configuration management program is managed and configuration management principles applied as a value-added process.

\subsection{PROGRAM PLANNING}

Program planning sets the direction, definition, and graded approach for future development and implementation activities necessary to establish an integrated configuration management program. This planning evaluates configuration management related requirements and needs, considers existing programs and procedures, and provides a strategy for corrective measures to align with the configuration management program elements.

The established work breakdown structure (WBS) for TWRS configuration management is presented in Appendix A. The WBS is not expected to be applied to all Departments. Only those elements that are necessary for the Department to implement and maintain the Department configuration management responsibilities should be included in the appropriate Department/Group WBS. This will allow integration of the necessary implementing tasks with the established configuration management WBS.

Configuration management performance measures are developed early in the program development. Performance measures use information from configuration management assessments and other sources (e.g., audits, Defense Nuclear Facility Safety Board findings, etc.). WHC-SD-WM-CM-007, "Configuration Management Compliance Matrix for Waste Tank Farms and the 242-A Evaporator of Tank Waste Remediation Systems," will be revised and updated, and will be used to guide development of the program. Ongoing internal reviews and/or program assessments will be performed to regulatory requirements and industry standards, and TWRS needs to identify necessary configuration management program improvements.

\subsection{CONFIGURATION MANAGEMENT TRAINING}

As the configuration management program is developed and procedures and related configuration management processes are established, associated training is required to communicate objectives and expectations- and to ensure effective implementation... The configuration management program training includes configuration management concepts, terminology, implementing procedures, and roles and responsibilities. The training process consists of the following:

- Initial awareness overview training for all management and implementing personnel. 
- In depth training for all personnel responsible for configuration management program management. Qualifications will be documented. (Baseline Development and Management Systems personnel currently managing the overall TWRS Configuration Management program are certified by the Arizona State University and the Institute of Configuration Management.)

- Training on functional and organizational implementation for personnel participating in day-to-day activities.

- Training on the integrated change control process for all participating personnel with detail commensurate with the individual change control function.

- Refresher training, as needed, for maintaining implementation, program reviews, and change practices.

Specific configuration management training will be developed as required. Integration with other training requirements is established through site training programs. The configuration management training applicable at the Division level will be developed and administered through the site training program.

\subsection{VENDOR AND CONTRACTOR CONTROL}

Vendor and contractor control ensures that important activities and information that support the TWRS configuration management program are reviewed and approved. Instructions (e.g., contracts, Statements of Work, Letters of Instruction) provided to vendors and contractors require these parties to include configuration management in their procedures for the conduct of work. Vendor and contractor control requirements include the following.

- Vendors and contractors establish controls over the products, product information, schedule, and cost as defined in this CMPP.

- The product configuration agrees with all product information, including approved changes.

- All approved changes are incorporated before final turnover to the next participant.

- Construction, modification, and as-built design drawings and documents are provided in a format that complies with the document control system established for the Hanford Site.

- Pertinent vendor technical information (manuals and notices) are identified, reviewed for acceptance by the operations function, collected, and controlled in accordance with WHC-CM-6-1, Standard Engineering Practices, EP-3.3, "Vendor Information Requirements."

- Other product information is provided in a format that complies with the document control and records management system established for the Hanford Site. 


\section{$2.4 \quad$ INTERFACES}

Organizational and technical interfaces necessary for the success of the TWRS configuration management program are identified, established, and controlled. Appropriate program and organization interfaces are presented in the elements of the configuration management program and the roles and responsibilities (see Paragraph 3.0) of this CMPP. Interface control is addressed in the TWRS Interface Control Working Group (ICWG) Charter, developed by TWRS Technical Integration and in the procedures referenced below.

The ICWG identifies, establishes, negotiates, and documents physical and functional interfaces. The identification of interfaces are initiated by the TWRS Technical Integration function of Safety and Technical Integration. Once identified, the details defining the interfaces are developed, negotiated, and agreed to by the affected organizations. The interface information is formally documented (drawing or text-type document) and formally controlled. Once documented, changes to the interfaces are made in accordance with Paragraph 6.0 of this CMPP. The process of creating functional interfaces will be defined in a future TWRS Technical Integration procedure.

The identification and control of technical interfaces at the Site and Program levels is in accordance with WHC-CM-6-1, EP-1.5, "Interface Control Requirements."

\subsection{PROCEDURES}

The procedures identified in this CMPP provide the details and process flows that implement this CMPP. Procedures that apply to all TWRS organizations are necessary to address the configuration management functions of program management, configuration item scope criteria, integrated baseline control, change control, configuration status, and assessments. The procedures will implement configuration management principles specific to the organization, discipline, and tasks covered by the procedure. Emphasis will be placed on making configuration management inherent in TWRS procedures and processes (engineering, operations, maintenance, etc.)

A phased and graded implementation plan (WHC-SD-WM-CM-014, TWRS CM Program Implementation Plan) is necessary for the successful execution of this CMPP. The implementation plan will be developed based on the initial assessments, audits, standards/requirements identification documents (S/RIDs), and existing WHC procedures. The TWRS CM Program Implementation Plan will delineate responsible organizations, the actions they will take to satisfy configuration management criteria, and implementation dates for those actions. The implementation tasks will be included in the activity planning documentation and milestone description sheets.

Procedures are reviewed and evaluated as to the need for the procedures and their usefulness in implementing the TWRS configuration management -program. Procedures -will be revised, superseded, canceled, or issued as necessary. Emphasis will be placed on minimization of procedures and use of existing procedures where possible. 


\subsection{DATA MANAGEMENT}

Databases, systems, and processes will be reviewed and evaluated as to their usefulness in implementing the TWRS configuration management program. These will be enhanced as necessary on a prioritized basis. Existing databases will be used to the maximum extent practicable. Duplicate databases will be consolidated for a cost effective use of information. This may encompass several databases used for purchasing, equipment maintenance, document control, and other activities. Additional database needs will be identified and fulfilled, as necessary, when current databases do not satisfy the necessary detail to effectively manage the information to support TWRS.

Databases used for configuration management require the same level of control as the data/ information contained in them. Databases that support the configuration management program identify computer software, documents, design bases, design requirements, schedule and cost baselines, and change request status to identify, store, control, status, and retrieve information.

- The Engineering Release System Database (ERSDB) tracks the status of released engineering documents and the subsequent changes to those engineering documents. Records Management Information Systems/Information Search and Archival (RMIS/ISEARCH) provides search, retrieval, and image access capability.

- A new interface database, developed and controlled by TWRS Technical Integration, will provide the following information:

- Interface identification number

- Title of the interface

- Organizations involved in the interface agreement

- Status of interface approvals.

- The new master equipment list (MEL), consistent with the product scope, is developed and maintained by the Design Authority.

- The systems engineered TWRS technical baseline is maintained on an existing database as part of the Hanford Site Technical Baseline. These information related products are controlled in accordance with WHC-IP-1117, Systems Engineering Manual, Part III, "Configuration Management Procedures," and WHC-SD-GN-CM-2001, Configuration Management Program Plan for Hanford Site Systems Engineering."

- The existing automatic data processing of the job control system provides support for TWRS facility maintenance and modifications.

Other existing databases used for configuration management include Vendor Information, Trending, Predictive Maintenance, Equipment Status, Label, Spare Parts Warehouse, Preventive Maintenance and Scheduling, Procurement, Maintenance Procedure, and the Integrated Project Information Management System. 


\subsubsection{Computer Software Configuration Management}

Computer software is identified, developed, documented, changed, and controlled in accordance with the requirements and procedures established in WHC-CM-3-10, Software Practices, and facility-specific instructions.

Access controls are provided to help ensure that only correct versions of the computer software are in use and to:

- Prevent unauthorized usage of the computer software.

- Identify the location and user of each copy of the computer software.

- Restrict copies of computer software to authorized users.

- Ensure that only the authorized computer software developers are allowed to make computer software revisions.

Steps are taken to provide backup and recovery if conditions cause loss of the program and/or data.

- Media control is applied to ensure that computer software is periodically backed up during development to allow full reconstruction of the computer software within a few work days.

- Backup computer software is stored in a location that is sufficiently distant from the application location so that a single disaster will not damage the media in both locations.

- Software is backed up at each revision so that previous revisions can be re-established.

Supplier provided software falls into two groups: vendor-provided and subcontracted software.

- Vendor-provided software is software that is privately developed or existing software such as operating systems, compilers, word processing tools and database management systems. Vendor-provided software must conform to an acceptable form of software configuration management. If the vendor does not have an adequate software configuration management program, the vendor can be disqualified from providing - software.

- Subcontracted software is any developed software that is unique or dedicated under contract to a facility. Any subcontractor wishing to do business with a facility must conform to an acceptable form of software configuration management. If the subcontractor does not have an adequate software configuration management program, the subcontractor must conform to all provisions (as modified for their specific use) of this CMPP. Any subcontractor not willing to abide by the above provision may be disqualified. 
WHC-SD-WM-CM-013

Rev 0

This page intentionally left blank. 


\subsection{ROLES AND RESPONSIBILITIES}

This section of the CMPP identifies general organizational roles and responsibilities. Specific configuration management activity responsibilities are be defined in WHC-SD-WM-CM-014.

To ensure implementation and program success, the roles and responsibilities are defined so the functional organizations are aware of the roles and responsibilities required for implementation of the configuration management program. Configuration management is integral to each person's tasks relative to program life cycle, which includes the development, fabrication, delivery, operation, and disposal of a product and product information. The following organizations are obligated to initiate actions at the beginning to implement the elements of configuration management throughout all tasks for which they are responsible and to maintain configuration management to ensure the identification and control of the TWRS integrated baseline, its component baselines, and changes thereto.

\subsection{U.S. DEPARTMENT OF ENERGY}

\subsubsection{Department of Energy, Headquarters}

DOE-HQ has overall responsibility for the Hanford Site as identified in DOE/RL-93-0106.

\subsubsection{Department of Energy, Richland Operations Office}

The DOE Richland Operations Office has overall responsibility for program execution guidance and business management guidance under DOE-HQ strategic direction and policies. Specific responsibilities are outlined in the Hanford Management Plan.

\subsection{MANAGEMENT AND OPERATING CONTRACTOR}

As the management and operating (M\&O) contractor, WHC establishes and manages the configuration management program by developing and establishing requirements and appropriate implementing procedures that address configuration management responsibilities and process methodologies. WHC is responsible for performing tasks relative to development, maintenance, and implementation of the TWRS configuration management program.

\subsection{SYSTEMS INTEGRATION}

The Systems Integration manager is responsible for the integrity of the Hanford Site Technical Baseline. Systems Integration-is responsible for ensuring that the-necessary-processes are in place to provide for and maintain that integrity. 


\subsection{WHC/CF KH SITE ENGINEER}

The Hanford Site Engineer is responsible for implementing and maintaining the integrated engineering process for the site, implementing the Design Authority/Design Agent system, and approving designated TWRS Design Authorities.

\subsection{TANK WASTE REMEDIATION SYSTEM}

TWRS, via the TWRS Vice President, is responsible for directing the tasks relative to development, maintenance, and implementation of the TWRS configuration management program.

The TWRS Management Systems, Disposal Program, Safety and Technical Integration, Characterization Projects, Transition Projects Departments, and Operations and Maintenance Programs are responsible for performing tasks relative to development, maintenance, and implementation of the TWRS configuration management program as identified in WHC-SD-WM-CM-014. All TWRS Departments will coordinate with Management Systems for the integration of implementation tasks.

\subsection{EMERGENCY, SAFETY, AND QUALITY SERVICES}

Emergency, Safety, and Quality Services (ESQ) implements quality programs and audits to ensure quality programs are accomplished. ESQ provides the necessary interface with the TWRS configuration management program identified in this CMPP to ensure configuration management elements are included in audits and audit information is provided to TWRS Management Systems for assessment of configuration management program implementation.

\subsection{BCS RICHLAND (BCSR)}

BCSR is responsible for managing information resources, document control, and records on the Hanford Site and for ensuring those used by TWRS or on behalf of TWRS are managed to meet the requirements of this CMPP. The Hanford Site records include those turned over by all participants.

\subsection{OTHER PARTICIPANTS}

Other participants are responsible for determining and implementing organization-specific configuration management implementation details in accordance with this CMPP. 


\subsection{CONFIGURATION ITEM SCOPE CRITERIA}

A graded approach is used to determine the appropriate resource level that is applied when implementing configuration management. The goal is to apply the necessary level of resources and to avoid expenditures when they are not warranted. The graded approach does not relieve participants from meeting contract requirements, but permits flexibility in the depth and rigor with which requirements are implemented.

\subsection{PROGRAM SCOPE}

At a project or facility level, grading is applied to determine what to include within the scope of the configuration management program and to what elements and depth configuration management is applied. Once the scope of configuration management program is determined, further grading is applied to the products. The elements included in the scope of the configuration management program are identified in configuration management program documentation, which may be in program or project plans. Defining the scope is based on:
- Owner direction
- Life cycle phase
- Program, project, or facility type and technical characteristics
- Program, project, or facility interfaces
- Desired lifetime and remaining lifetime
- Adequacy of existing controls and procedures
- Operational status.

\subsubsection{Owner Direction}

The DOE may place requirements on various activities based on their determined need for information and control. New acquisitions, especially major system acquisitions, usually require that full configuration management (see Appendix B, "Graded Approach") be applied to ensure an operational product on turnover that meets the requirements and with which the documentation agrees.

\subsubsection{Life Cycle Phase}

The life cycle stage of a project or facility is a significant factor in establishing the scope of the configuration management program. As mentioned in Paragraph 4.1.1, new projects usually require a full configuration management program. The configuration management program scope for an operating facility concentrates resources on the SSCs needed for operation, whereas facilities that are no longer operational and are entering decontamination and decommissioning (D\&D) or environmental restoration (ER) have fewer SSC\& within the-configuration management-scope. Transition processes between life cycle phases are planned and documented to maintain the required configuration. Refer to Figure 2, page 2.

\subsubsection{Facility Type and Technical Characteristics}

The consideration for facility type and technical characteristics is applied to determine the implementation actions that would be appropriate for the facility when the configuration management program is fully implemented. The general program criteria is reviewed based on the facility type 
and technical characteristics to determine which are appropriate, which need adaptation, and which are not applicable. A management system is influenced less by facility type and technical characteristics than a program of technical criteria (hardware) would be.

\subsubsection{Project or Facility Interfaces}

Consideration is given to the interfaces with activities that require configuration management to ensure those activities are not degraded by the scope of an interfacing program. Each program activity is scrutinized to ensure interfacing activities and programs are not degraded. An interface control program is required to ensure the integrated baseline is maintained.

\subsubsection{Facility Desired/Remaining Lifetime}

If the performance lifetime is known and there is no intent to extend operations (another campaign), then the scope of the program is known. If, however, other uses are found or another campaign is desired, then life extension should be planned in the configuration management program. This lifetime consideration is included in Appendix B, "Graded Approach."

\subsubsection{Adequacy of Existing Controls and Procedures}

A review is undertaken when establishing this configuration management program to determine the extent of procedures and controls that exist and are being used. Some of the controls and procedures may satisfy the needs established for the program scope and SSC grading for the planned program. Where adequate procedures and controls do not exist, it is necessary to modify or develop and implement new procedures and controls.

\subsubsection{Facility Operational Status}

Operating facilities require a fully implemented configuration management program. Facilities in a non-operating status and maintaining the capability to resume operations implement those configuration management activities that are important to ensure that the physical configuration does not degrade and that changes are identified and approved. Facilities in a non-operating status and not maintaining the capability to resume operation undertake those configuration management activities that are important to track changes and provide documentation of the SSCs that remain in the facility. Walkdowns are conducted to confirm that the configuration in the documentation is accurate.

\subsection{EQUIPMENT SCOPE CRITERIA}

The SSCs that are in the TWRS configuration management program will be identified. Details of equipment-scope grading are found in Appendix B. Some-of the documents to be used in the compilation and maintenance of the SSC list are:

\footnotetext{
- Authorization Basis documents

- Safety Basis documents

- Safety analysis reports

- Interim safety equipment lists

- Safety equipment lists

- Essential drawings
} 
- Results of operational readiness reviews

- Facilities interim safety bases.

The specific equipment list, usually in the form of a database, identifies the specific SSCs that will be included in the configuration management program. This equipment list should be in the form of a MEL. The Safety Equipment List (SEL) is a subset of the MEL. As a minimum, the equipment list will provide the following information:

- Structures and systems that are in the TWRS configuration management program

- Components that make up each system

- Grade of each system and component

- Reference to appropriate requirements and design basis documents for each SSC

- Cognizant engineer

- Design Authority

- Responsible organization

- Source of requirements. 
WHC-SD-WM-CM-013

Rev 0

This page intentionally left blank. 


\subsection{BASELINE MANAGEMENT}

To provide for management of the baseline, all programs/projects must identify the technical baseline (including bases) that will be supported, define the related tasks to be performed, provide a schedule for accomplishing the tasks, and identify the resources required to produce acceptable end products. Baseline management combines technical, schedule, and cost information into a single integrated baseline. Baseline management is provided through coordinated implementation of configuration management and other program management processes (e.g., cost and schedule control).

\subsection{TECHNICAL, SCHEDULE, AND COST INTEGRATION}

As shown by Figure 3, the technical requirements are developed from the technical basis. The technical requirements act as a basis for the WBS, which in turn acts as the basis for developing the schedule and cost information. Integration of the technical baseline with the cost and schedule baselines ensures that management has control of the technical scope related to the cost and schedule elements. This integration provides further assurance that valid information is available to accurately assess the cost and schedule impacts that may be associated with proposed changes to the technical baseline and to evaluate cost and schedule changes for technical impacts. Integration of the technical, schedule, and cost is performed by mapping (matrixing) the WBS to the products defined within the technical baseline. Schedule and cost information is developed using the WBS and WBS dictionaries.

Figure 3. Technical, Schedule, and Cost Integration.

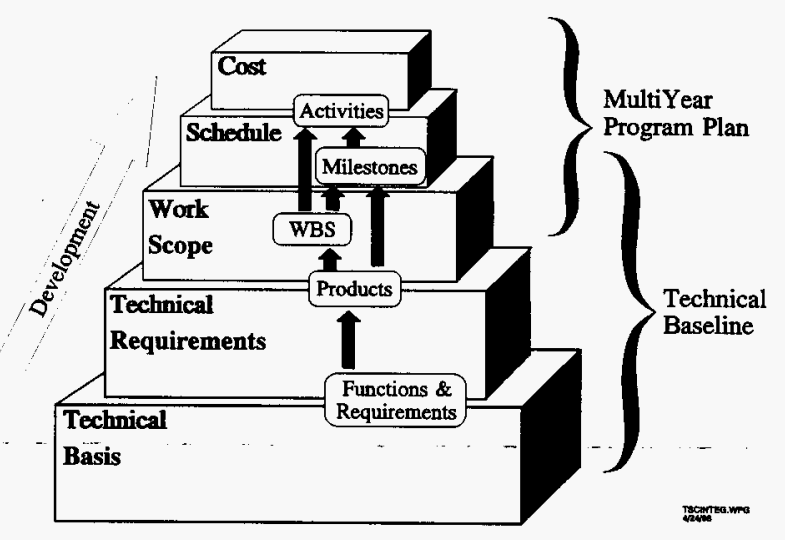




\subsection{TECHNICAL CONTROL}

This section describes the process for identification, documentation, and control of the technical baseline. Change control is addressed separately in Paragraph 6.0 .

A technical baseline is that body of technical information associated with a product under development, operation, modification, or deactivation. This baseline is the reference set of technical data and is controlled using configuration management as described in this CMPP. All documents in the baseline related to a product will be prepared in accordance with the applicable procedures. As development of the baseline evolves, required product information will be developed or changed and controlled throughout the life cycle using configuration management procedures.

The technical baseline is developed in stages that are named for the related life cycle phases (see Figure 2, page 2). Each baseline contains the appropriate level of evolving technical information based on the maturity of the system. The technical baseline provides a controlled frame of reference to progressively expand the system definition and design and is available to all TWRS participants. The development (specific documents, data, and information) and maintenance of the TWRS technical baseline is defined and governed by WHC-SD-WM-SEMP-002. The following is a brief description of the various baseline evolutions and the purpose of managing each evolution. Refer to WHCSD-WM-SEMP-002 for more information about each baseline evolution.

- Functions and Requirements Baseline. This baseline begins with Mission Analysis and includes development of the Functions and Requirements Document (FRD) and Baseline System Description (BSD). From the mission objectives, the functional requirements provide the necessary basis for development of system-level requirements. A requirements database is established (may be included as a part of the equipment list database) and is maintained throughout the program or project life cycle. Requirements traceability will be maintained through the requirements database. After approval, release and subsequent implementation of the systems requirements documents, the technical baseline will continue to evolve. This functional configuration is managed to provide for traceability of bases and retrievability of functions, requirements, and bases information.

- Technical Requirements Baseline. This baseline includes the Technical Requirements Specifications (TRSs), Interface Control Documents (ICDs), and updated BSD. At this point, the technical baseline represents the technical approach chosen to accomplish the program mission and provides the technical basis for assigning functions to projects. This technical requirements baseline is managed to provide agreement and traceability among the functions, requirements, and bases information.

- - Design-Requirements Baseline: This baseline-includes the-Design Requirements Documents (DRDs), ICDs and updated BSD. At this point, the baseline provides the essential technical requirements for designing, constructing, operating, and maintaining the system. This baseline identifies the functions and requirements allocated to each project. This design requirements baseline is managed to provide agreement with the technical requirements baseline and provide traceability and retrievability of the requirements and bases. 
- Design Configuration Baseline. The Design Configuration Baseline is established at the end of conceptual design and continues developing through design and construction. This baseline includes the Project Development Specification (PDS), Project Design Concept (PDC), Project ICDs, updated DRDs, and other detailed design documents. At this point, the technical baseline refines requirements to reflect final design decisions. The final design will provide the details of the design necessary for fabrication, assembly, construction, installation, and testing of SSCs. The design configuration baseline is managed to provide traceability to the design requirements baseline, to establish and maintain consistency and traceability between functional and physical configuration items with related requirements and basis, and provide for retrievability of the design.

- Operational Baseline. This baseline documents the completion of turnover to operations. It includes updates to the prior baseline products and the construction, test, and turnover package and operations and maintenance packages that document the actual configuration of each project. This baseline is managed to provide traceability of the technical basis for continued operations, maintenance, and upgrades and retrievability of the operational baseline for maintenance and modification. The technical baseline during this phase will be updated throughout the operational life of the system to reflect the actual TWRS operational configuration. Emphasis is placed on maintaining the baseline traceable to and in compliance with the Authorization Basis. The Operational Baseline is managed to provide traceability to the design requirements baseline, establish and maintain consistency and traceability between functional and physical configuration items with related requirements and basis, and provide for retrievability of the design. Facilities (operating plants) maintain the operating configuration (current alignments, limits, calibrations), operating procedures; and the physical facility (equipment, spare parts, labeling) consistent with and traceable to the design requirements of the facility and within the Authorization Basis for the facility.

During the operational phase, specific information should be collected, categorized, and retained to support the generation of the Transition Project's turnover package to D\&D. Examples of this information are:

- Product/facility historical information

- Appropriate safety analyses documents and facility emergency procedures

- List of operational equipment

- Records of crane load certification-tests and preventive-maintenance records

- Descriptions of inaccessible areas and why

- Identification and quantification of all hazardous material that is in the facility

- Radiological and toxicological status surveys

- Documents that show hazardous material has been removed from the facility 
- $\quad$ A record of removed circuit breakers and disabled circuits

- A record of blanks that were installed and remain after facility turnover to Transition Projects.

- Decontamination and Decommissioning Baseline. This baseline documents the configuration at the beginning of facility deactivation after normal facility operations have ended. It begins from operational configuration and includes all approved changes. This baseline is managed to provide the traceability and retrievability of the end state of the operational baseline as a basis for future work.

\subsubsection{Establishment and Control of Design Bases}

Design bases and changes to them (the evolving baseline) are documented, correlated with, and maintained traceable to the resultant design requirements and products. Design verification is performed to ensure valid design bases. Changes to design bases are evaluated for impacts to the related requirements and products. Impacts are dispositioned to ensure continued consistency among design bases, requirements, and product information. Design bases are identified, established, documented, and maintained in accordance with WHC-CM-6-1. Authorization Basis information is included in this design bases information. The principal types of design bases are described as follows.

- Design Inputs - Those specific criteria, limits, bases, or other initial requirements (such as specific functional requirements, specific codes and standards, and specific regulatory commitments) on which the detailed design is based.

- Design Constraints - Those general restrictions and limits to the engineering design process that ensure consistency and quality of designs (such as general codes and standards, general regulatory commitments, quality assurance requirements, engineering procedures and good practices, and required design methodologies).

- Design Analysis and Calculations - Those intermediate design products that are necessary to convert the design inputs and constraints into appropriate and complete design outputs. These consist of a wide variety of engineering analyses, calculations, studies, reports, and technical review checklists necessary to perform complete engineering design.

\subsubsection{Establishment and Control of Requirements}

Requirements are generated from the verified, valid, and authorized basis. Changes to the design requirements-are-reflected in-design outputs-and-products-and are-maintained traceable to, consistent with, and supported by the design basis. Operating, maintenance, and testing procedures are included in the list of requirements documents that are maintained consistent with the design requirements.

Requirements and changes (e.g., modifications) to them are formally established, documented, and maintained. Requirements reflected in the design outputs (drawings, specifications, supporting documents, etc.) or the "as-designed or as-operated conditions," are the documented products of the 
design process that specify the design requirements for TWRS products. Design requirements and design bases are documented and maintained in accordance with WHC-CM-6-1.

- The design outputs are the composite result of the consideration of the design inputs, design constraints, and design analysis and calculations.

- Design outputs specify the functions, capabilities, capacities, physical dimensions, limits and setpoints (such as valve, switch, and relay positions), etc., that are necessary and supported by the design basis.

- Design outputs include the functional requirements, as well as procurement requirements, quality assurance actions, construction installation specifications and instructions, post-installation testing, post-maintenance testing, and periodic surveillance/testing requirements.

- The design outputs provide the design requirements that dictate the physical configuration of the project. This includes configuration information such as waste tank content characterization data.

The source of requirements should be included in the TWRS MEL, which correlates the requirements with the SSCs involved, the SSC grade, technical topics involved, and associated design and configuration management documentation.

The requirements for new projects and modifications to existing facilities are established, categorized, and documented as they are developed.

\subsubsection{Control of Interfaces}

System and process boundaries are established to contain those SSCs that are necessary for facility operations. The WHC interface control documentation is established in accordance with WHC-CM-6-1, EP-1.5.

- Construction Projects. An ICWG should be used to identify, establish, document, and control all physical and functional interfaces of SSCs. See Paragraph 2.4 of this CMPP.

- All interface boundaries are documented and formally controlled as soon as they are developed and approved.

- Interface control documents and their related changes are processed in accordance- with WHC-CM-6-1, EP-1.5.-

- Existing Facilities. An ICWG is used to identify, establish, document, and control all physical and functional interfaces within the configuration management program. See Paragraph 2.4 of this CMPP.

- All interfaces are documented and formally controlled as soon as they are developed and approved. 
- $\quad$ Procedures are developed to process interface control documents and their related changes.

- A graded approach is used to ensure that the level of interface control is consistent with the requirements and needs of the facility.

- A graded approach is used for any reconstitution effort that is conducted to establish interface control information.

\subsubsection{Turnover}

Formal criteria for the turnover (design to construction, construction to operations, operations to decommissioning, etc.) of new facilities or new modifications will be established. Effective interface is established early in the design process to ensure needed design products will be provided and turnover is successful. For successful turnover the following actions are required:

- Using Letters of Instruction (LOI), Statements of Work (SOW), specifications, and contracts that clearly identify requirements

- Identifying format and content of design basis and design output documents

- Periodically monitoring the preparation of design basis and design output documents

- Providing review and approval of the format and content of the final design basis and design output documents and accepting responsibility for their configuration management at turnover.

New projects follow a documented turnover process identified in DOE 4700.1. Other projects may require readiness reviews before operating. Readiness Reviews are addressed in WHC-CM-1-5, Standard Operating Practices, Section 1.2, "Startup and Restart of Facilities." Acceptance tests and operability tests are performed. Information on acceptance tests and operability tests are found in WHC-CM-6-1 and WHC-IP-1026, Engineering Practices Guidelines.

\subsection{SCHEDULE CONTROL}

Schedules are developed in an electronic form that can be linked and sorted to provide an integrated TWRS baseline. The integrated TWRS baseline is then provided as a summary level component for the DOE Integrated Site Baseline. The scheduling software selected must be compatible with other scheduling software being used to enable the combining of information. The schedule information for accuracy, efficiency, and economy must be-useable at the program/project level and be a part of the DOE Integrated Site Baseline without intermediate translation or manipulation. The information required includes activities, durations, logical relationships, milestone dates, actual start, actual finish, and progress. Other information may be required to satisfy program/project needs. Change control is addressed in Paragraph 6.0 of this CMPP. Scheduling information is found in WHC-CM-2-5, Management Control System, and WHC-IP-0842, TWRS Administration Manual. 


\subsection{COST CONTROL}

Costs are derived from the technical baseline through the developed WBS and are identified by costed resources in the schedule. The costed resources are grouped by cost accounts that are directly traceable to the technical baseline via the WBS. Change control is addressed in Paragraph 6.0 of this CMPP. Cost control information is found in WHC-CM-2-5.

\subsection{PRODUCT INFORMATION CONTROL}

The product information is identified and maintained consistent with the functional and physical configuration and design requirements. This is accomplished by identifying the product information to be controlled, documenting it, and storing, controlling, tracking, and retrieving the documents, product information, and changes.

A graded approach (Paragraph 4.0) process identifies the document types and the specific documents that are required for each product controlled by the configuration management program.

Each participant maintains a list (tree) of controlled documents/products in planning or operating documents. All controlled documents are entered in the site document control and records management system.

\subsubsection{Documentation of Design Requirements}

Requirements are reflected in the five current major categories of engineering documents: drawings, specifications, vendor information, supporting documents, and selected types of environmental engineering documentation.

All configuration management documents have unique identification numbers to facilitate document retrieval, statusing, change development, and links to other documents and products.

- Drawings. All TWRS drawings are prepared and released in accordance with the requirements of WHC-CM-6-1, EP-1.3 "Engineering Drawing Requirements."

Each item (e.g., assembly, subassembly, component, and detail part) that is fabricated, assembled, installed, and/or procured will be identified by one part number that is the drawing number and dash number (where used) of the drawing where captive details are reflected on an assembly, installation, or other construction drawing on which the item is defined. General requirements for hardware/equipment identification selection will be in accordance with Hanford A/E General Standards, GG-DWG-01, - -02, $-03, .=04$, and . -05 . Part numbers are assigned to identify a specific item in accordance with WHC-CM-6-1, EP-1.3.

- Specifications. Specifications are prepared and released in accordance with WHC-CM-6-1, EP-1.2, "Engineering Specifications Requirements."

- Vendor Information. Vendor information is collected, identified, and controlled in accordance with WHC-CM-6-1, EP-3.3. 
- Supporting documents. Supporting documents are prepared and released in accordance with WHC-CM-6-1, EP-1.12, "Supporting Document Requirements."

- Environmental Engineering Documentation. Environmental engineering documentation is prepared in accordance with WHC-CM-3-6, Uniform Publications System, and released in accordance with WHC-CM-6-1, EP-1.6, "Engineering Data Transmittal Requirements," and EP-1.7, "Engineering Document Review and Approval Requirements."

Drawings and specifications are used for final design requirements. Vendor information, supporting documents, and environmental documents supplement the final design requirements.

\subsubsection{Documentation of Design Basis}

Design basis information is identified in supporting documents that are prepared, released, and revised in accordance with WHC-CM-6-1, EP-1.12. Design basis information is developed through the systems engineering process and may be retained in the systems engineering database, the control of which is documented in supporting documents. The design basis is maintained traceable to the dependent design requirements and decisions.

\subsubsection{Operating and Maintenance Documentation}

TWRS operating documents (except Analytical Labs) are prepared, released, and controlled in accordance with WHC-IP-0842, Volume II, Section 4.16.1, "Operating Document Control." TWRS maintenance documents (except Analytical Labs) are prepared, released, and controlled in accordance with WHC-IP-0842, Volume V, Section 5.1, "Maintenance Document Control." TWRS Analytical Labs administrative, operating, and maintenance documents are prepared, released, and controlled in accordance with WHC-CM-5-4, Laboratories Administration, Section 3.9, "Laboratory Procedures."

\subsubsection{Document Owners}

Document owners (Design Authority, responsible organization, or responsible person) are responsible for establishing, verifying, and maintaining control and traceability of the technical content of assigned documents. Document owners are also responsible for ensuring configuration management records are correct when transferring document ownership. The configuration management processes will be enhanced to provide for ongoing identification of document owners.

\subsubsection{Document Approvals}

Minimum approval requirements for documents important to the environment, safety, or quality are in accordance with-WHC-CM-3-5, Document Control and-Records Management Manual, Section 12.7, "Approval of Environmental, Safety and Quality Affecting Documents."

\subsubsection{Identification of Documents}

Document types included in the TWRS CM program are identified based on the product supported by the document and the intended and actual use of the document. Documents that establish or communicate configuration information for configuration items (see Paragraph 4.2) will be included within the TWRS CM program. These configuration documents will be traceable to the 
associated product. Configuration documents that identify product performance are traceable to the WBS and the associated product.

- TWRS determines the types of documents that will be included in the configuration management program based on this CMPP.

- A graded approach (see Appendix B) identifies the document types and the specific documents that are required for each SSC that is controlled by the configuration management program.

- Each document will have identified document owners.

- Document owners will verify the technical content of assigned documents.

- Each document is identified in accordance with the procedures listed in Paragraphs 5.5.1 and 5.5.3. All configuration documents have unique identification numbers that facilitate document retrieval, statusing, change development, and links to other documents and SSCs.

\subsubsection{Storage}

Responsibilities for document archival storage, permanent storage for one-of-a-kind records, and access control are established, and original or master copies of configuration documents are stored and protected in accordance with WHC-CM-3-5.

\subsubsection{Control and Tracking}

The ERSDB is the master document control and release system database for statusing engineering documents and related changes. The status of each approved change is maintained, and all released changes are tracked to work completion.

- TWRS uses Document Control Services (DCS) for release and statusing of documents and related changes required to control the accurate representation of a facility's configuration. The requirements for use of this document control system are specified in WHC-CM-6-1, EP-1.7.

- Only the current approved version of a document and related outstanding engineering change notices (ECNs) of identified documents are used.

- Documents listed in the ERSDB can identify documents related to particular SSCs, types of SSCs, technical topics, and -other relational-information-as may be necessary.

Control and tracking of operating and maintenance documents is performed by the organizations listed in Table 1. 
Table 1. Document Source/Location.

\begin{tabular}{|c|c|c|}
\hline TYPE & DOCUMENT SOURCE & LOCATION \\
\hline $\begin{array}{l}\text { Active Drawings \& ECN's \& } \\
\text { Search capacity for Engineering Documents by Key } \\
\text { Word/Building/Number/etc. }\end{array}$ & $\begin{array}{l}\text { Document Control Services } \\
\text { (DCS) }\end{array}$ & $\begin{array}{l}\text { See HLAN, Hanford } \\
\text { Info for Location }\end{array}$ \\
\hline $\begin{array}{l}\text { Same as above } \\
\text { (Only Center with ALL Drawings, Revisions, and some } \\
\text { Vendor Files) }\end{array}$ & DCS (History) & $\begin{array}{l}\text { MO-47/200E/131 } \\
\text { VISIT } \\
\text { (Do Not Phone) }\end{array}$ \\
\hline $\begin{array}{l}\text { Active Projects in work - } \\
\text { Provide Project No. to get Box No. at Bldg. } 712 \text {, as applicable }\end{array}$ & Construction/Project Files & $\begin{array}{c}2750 \mathrm{E} / 200 \mathrm{E} / \mathrm{D}-176 \\
373-3834\end{array}$ \\
\hline Vendor information files \& History Drawing's for Site & $\begin{array}{l}\text { Records Storage Services } \\
\text { (Vendor Info Files) }\end{array}$ & $\begin{array}{c}3707 \mathrm{D} / 300 / 6 \\
376-6411\end{array}$ \\
\hline Engineering Documents (copies) & DCS & $\begin{array}{c}3706 / 300 / 210 \\
376-5421\end{array}$ \\
\hline $\begin{array}{l}\text { Older Documents/Projects (will need box number, if in } \\
\text { Seattle) }\end{array}$ & Records Storage Services & $\begin{array}{c}\text { (RHA) } 712 / 700 \\
376-6584\end{array}$ \\
\hline $\begin{array}{l}\text { TWRS Operating Procedures (Except Characterization) } \\
\text { TWRS Administrative Procedures (Except Analytical Lab) }\end{array}$ & $\begin{array}{l}\text { Tank Farm Transition Projects } \\
\text { Procedures }\end{array}$ & $\begin{array}{c}* \\
2750 \mathrm{E} / \mathrm{D} 295 / 200 \mathrm{E} \\
373-4802\end{array}$ \\
\hline TWRS Maintenance Documents (except Characterization) & $\begin{array}{l}\text { Tank Farm Transition Projects } \\
\text { Maintenance Programs }\end{array}$ & $\begin{array}{c}* \\
2750 \mathrm{E} / \mathrm{D} 200 / 200 \mathrm{E} \\
373-2270\end{array}$ \\
\hline $\begin{array}{l}\text { TWRS Characterization Operations and Maintenance } \\
\text { Documents (except Analytical Lab) }\end{array}$ & $\begin{array}{c}\text { TWRS Characterization Project } \\
\text { Production Control/ } \\
\text { Maintenance/Material } \\
\text { Readiness }\end{array}$ & $\begin{array}{c}{ }^{*} \\
2704 \mathrm{HV} / \mathrm{B} 135 / 200 \mathrm{E} \\
376-2615\end{array}$ \\
\hline $\begin{array}{l}\text { TWRS Analytical Lab Administrative, Operating, and } \\
\text { Maintenance Documents }\end{array}$ & $\begin{array}{l}\text { TWRS Characterization Project } \\
\text { Program Mgmt \& Integration }\end{array}$ & $\begin{array}{c}\text { MO291/A159/200W } \\
373-3076\end{array}$ \\
\hline
\end{tabular}

Procedures can be accessed on procedure information system.

\subsubsection{Retrieval}

The responsibility for document retrieval and the document retrieval time is established as identified in WHC-CM-3-5.

- Documents are retrieved in a timely manner upon request.

- Identified documents are retrievable from BCSR.

- The required retrieval times for each document is based on the priorities established by the document owners and users.

- Document archival storage, permanent storage for one-of-a-kind records, access control, and microfilming of record documents are performed in accordance with in WHC-CM-3-5. 
- Originals and copies of identified documents (including approved changes) are stored, protected, and readily available to creators and users of the document at the point of application. The locations for storage access of documents are identified in Table 1.

- Retention times are established to meet the needs of the document owners and users (see WHC-CM-3-5, Section 4). All documents are retained until turnover to D\&D as part of the deactivation turnover package. After turnover, retention requirements are specified by the D\&D organizations performing the appropriate subsequent activities.

- When a copy of a document is issued, the document includes the identification of pending changes and the references to detailed information regarding such changes.

\subsection{MATERIAL CONDITION AND AGING MANAGEMENT}

Many of the facilities being used to clean up the Hanford Site may have their mission changed. Mission changes will require revision of the facility to support the new mission. When changes to the use of existing facilities or equipment are identified, the Material Condition and Aging (MCA) program is initiated, and a program plan and appropriate implementing procedures are prepared. The MCA Program Plan is based on implementation considerations and initial assessments and addresses the same topics identified in this TWRS CMPP. The scope criteria addressed in Paragraph 4.0 and graded approach detailed in Appendix B are applied to the MCA activities.

The MCA program assesses the material condition of potentially life-limiting components, estimates the remaining life of components, develops life-extension techniques of components, and develops analytical and periodic testing procedures to measure aging degradation trends.

\subsection{DESIGN RECONSTITUTION}

Aging facilities within TWRS may require update of product information to reflect the current configuration. The level of design reconstitution is based on the need to establish a sound basis for performing work and providing for the performance of related tasks. As-building is a part of a comprehensive Design Reconstitution Program that is applied based on the graded approach (see Appendix B). Limited design reconstitution may be performed in an as-building program where only the necessary design requirements that support the continued safe operation are validated (rather than validating all design requirements). The facility and design documents would reflect the actual existing facility configuration, which has been verified to be safe to operate. In such cases emphasis is placed upon establishing and maintaining compliance to the Authorization Basis.

Design reconstitution is a one-time effort of identifying, retrieving, evaluating, verifying, and regenerating missing design-bases and critical design requirements. Where-design information for an existing product is found to be inadequate, the design reconstitution program is used to establish, organize, and document design information for systems and technical topics. The adequacy of existing design information is technically evaluated to determine the extent and priority of the design reconstitution needed. Once reconstituted, the design is maintained as part of the existing baseline. Existing TWRS design reconstitution programs are described in WHC-SD-WM-CM-009, "Design Reconstitution Program Plan for Waste Tank Farms and Evaporator of Tank Waste Remediation System," and WHC-SD-WM-CM-011, "Hanford Site Waste Tank Farm Facilities Design Reconstitution Plan." 
WHC-SD-WM-CM-013

Rev 0

This page intentionally left blank. 


\subsection{CHANGE CONTROL}

The TWRS integrated baseline requires coordination and integration of changes and the various change control processes. The principle of change control is to maintain consistency among the requirements, product configuration, and product information as changes are made. The baseline is changed to allow product-related activities to evolve and progress through the product's life cycle. Close control of technical, schedule, and cost information ensures the baseline evolves in an effective and efficient manner. Change control is performed by all participants and is integrated through Change Control Administrators (CCAs) and ICWGs.

Change control for TWRS is the systematic evaluation and coordination process of maintaining the previously established technical, schedule, and cost baselines and identifying and controlling all changes to these baselines.

Site integration level procedures are found in WHC-IP-1117, Part III. Program change control is described in WHC-CM-2-5; WHC-CM-6-2, Project Management, PM-14, "Project Baseline Management and Change Control;" and participant-specific procedures. TWRS change control process is described in WHC-IP-0842.

\subsection{CHANGE MECHANISMS}

Each participant should identify and document the mechanisms that can lead to permanent or temporary changes to SSCs and/or documentation. The identification of change mechanisms aids in indicating when a change to a product is a change in the configuration and, as such, requires documentation of the change to ensure the change is defined, reviewed, and approved before implementation.

\subsubsection{Deviations}

Deviations are departures from a particular performance or design requirement of a contract, specification, or referenced document. Deviations require approvals before the deviation is allowed and work is performed. A deviation differs from an engineering change in that an approved engineering change requires corresponding revision of the documentation defining the affected product, whereas a deviation does not require revision of the applicable specification or drawing; however, the contract may be modified.

\subsubsection{Non-conformance}

A non-conformance is a deficiency in characteristics, documentation, or procedures that renders the quality of an item or activity unacceptable or indeterminate... Non-conformances may occur during the performance of work. Non-conformances require formal disposition and may result in revision of engineering documentation or procedures. A non-conformance is usually discovered during the performance of work. An evaluation is performed to determine if documentation defining the product needs to be revised or other disposition (accept, reject, or rework) needs to be made. 


\subsubsection{Directed Changes}

Directed changes are changes required by DOE. These include direction to change technical, schedule and/or cost baselines. Once received, directed changes are processed to identify impacts, determine how they can best be implemented, generate implementing change proposals, and to respond to the DOE regarding these items.

\subsubsection{Other Changes}

Other changes occur as a result of resolving deficiencies; improving procedures, costs, changes in priorities; identifying the need for design modifications; and so forth. The need for these changes are identified via the change control processes listed in Paragraph 6.3.

\subsection{IDENTIFICATION AND DOCUMENTATION OF CHANGES}

Changes are requested and identified using the form(s) required by the change control processes listed in Paragraph 6.1.3. All changes, whether temporary or permanent, to configuration managed products and product information are identified, documented, validated, dispositioned, implemented, and closed. The change is tracked from the point of identification through closure. The following is a list of the minimum information to be included in a change package being submitted for approval. Change requests may be initiated with partial information and developed during the review process to meet these minimums.

- A complete, clear, and accurate description of the change. Source material that requires or requests a change is identified or included as part of the change package. Types of source material may include non-conformance reports, software problem reports; and procurement, maintenance, and operations correspondence.

- A clear and accurate justification of why the change is required.

- Constraints and limits to what can be done during change implementation.

- Identification of all impacted participants.

- A description of the impact, including the products and documents that must be changed.

- A description of the consequences:

- If-the change-is not implemented or is not.implemented by the due date.

- If the change is implemented by the due date (what are the benefits).

- Results of analysis or calculations to support the change.

- A rough order of magnitude and bases of the complete cost of the change and source of funding to make the change. This is to be coordinated with other organizations and finalized during the change implementation development. 
- The estimated schedule for implementing the change. This is to be coordinated with other participants and finalized during change implementation development.

- Acceptance criteria after change implementation.

Change documentation evolves from identification of the proposed change, through reviews, disposition, implementation, post modification test results, as-built information and eventual closeout. These steps are traceable to technical, schedule, and cost impacts and are tracked by the CCAs. The closeout of the change includes updating all affected product information. Disapproved changes are closed out and include the reason for disapproval.

\subsection{CHANGE CONTROL PROCESSES}

Change processing is characterized by thresholds for review and approval with management involvement increasing with the importance of the change. Changes to each component (technical, schedule, and cost) that comprises the TWRS baseline and project baselines will always be evaluated for all impacts. Figure 4 portrays a typical change control process. The TWRS change control processes listed below emphasize those change control elements necessary for their application. Some elements (e.g., screening of requested changes) may be informal.

A change against technical, schedule, and cost baselines may require approval outside of TWRS (either WHC or RL). Changes not requiring approval outside of TWRS are limited to the TWRS review and disposition process. Changes to the Integrated TWRS Baseline (technical, schedule, or cost) are processed in accordance with:

- WHC-CM-2-5, Section 2.3, "Baseline Management," and Section 4.1, "Change Control"

- WHC-CM-6-2, PM-14

- WHC-IP-1117, Part III.

Other changes are processed using the appropriate change control process(es) listed below:

- Changes to engineering documents and other supporting documents are made in accordance with WHC-CM-6-1, EP-2.2, "Engineering Document Change Control Requirements."

- Changes to TWRS operating documents (except Analytical Labs) are made in accordance -with WHC-IP-0842,. Volume II, Section 4.16.1.

- Changes to TWRS maintenance documents (except Analytical Labs) are made in accordance with WHC-IP-0842, Volume V, Section 5.1. 
Figure 4. Typical Change Control Process

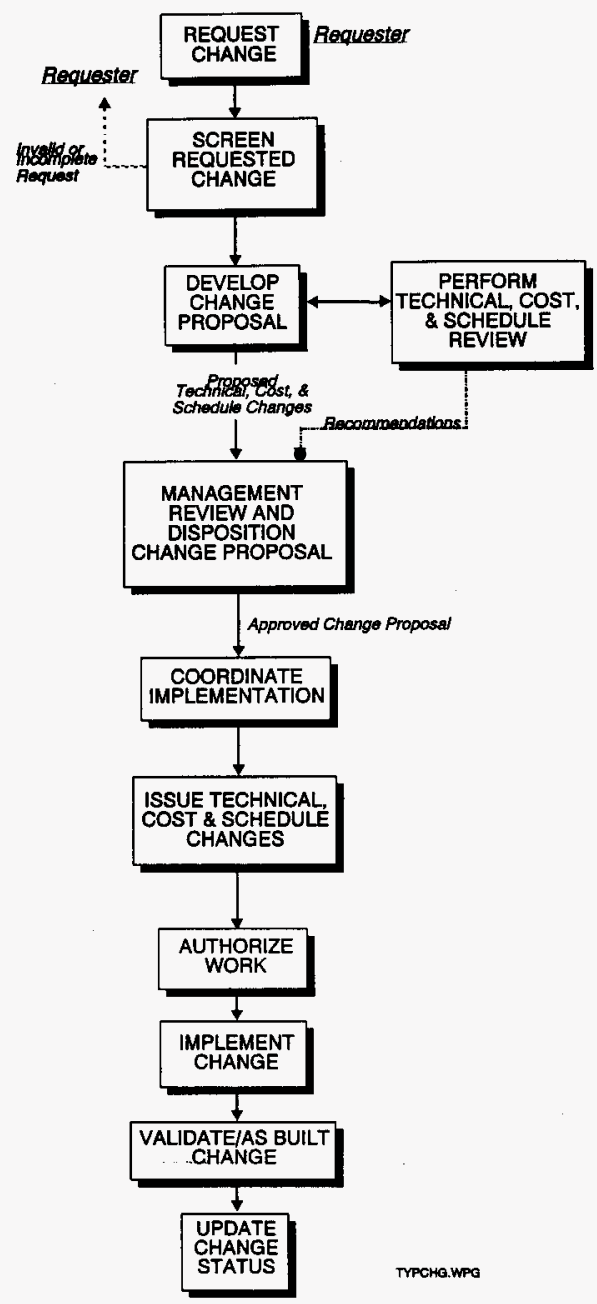


- Changes to TWRS Analytical Labs operating and maintenance documents are made in accordance with WHC-CM-5-4, Laboratories Administration, Section 3.9.

- Changes to computer software are made in accordance with Paragraph 2.6 of this CMPP.

- If a change involves an Unreviewed Safety Question (USQ) or potential USQ, the USQ is processed in accordance with WHC-CM-1-5, Section 7.3, "Identifying and Resolving Unreviewed Safety Questions," and facility-specific USQ implementation procedures.

\subsubsection{Request Change}

Changes may be initiated from many sources, including directed changes. Regardless of the source of the request/direction the change should go through the same process to ensure proper identification of impacts, enable appropriate decision making, and correct disposition of the proposed change. Change requests may be initiated with partial information and developed during the review process to meet the minimum criteria of Paragraph 6.2.

\subsubsection{Screen Requested Change}

All requested changes are screened to eliminate duplicate and invalid requests and to ensure the requests contain the proper amount of information. Screening is also used to prioritize the request for processing and make the management decision to develop the change.

\subsubsection{Develop Change Proposal}

Change proposals are developed using the form(s) required by the change control processes listed in Paragraph 6.1. Development involves representatives for impacted products and documents (affected program elements). The information necessary to meet the criteria listed in Paragraph 6.2 is developed to a point where the change proposal is ready for submittal to management for dispositioning. The final stages of development overlap the review process so that the change proposal developer(s) work with reviewers to address review comments before submittal of the change to management.

\subsubsection{Perform Technical, Schedule, and Cost Reviews}

The use of ICWGs as part of change reviews is an important element to ensure changes are integrated among affected program elements. It is possible that a proposed change will significantly impact other program elements so that the initiator of the change would not be able to make the change as proposed-- Earty-involvement of impacted participants helps prevent -and-resolve such problems. This interface must take place during change development.

Technical, schedule, and cost expertise appropriate to the complexity and importance of the change is applied. A technical, schedule, and cost review is not an approval, but improves the change package and makes recommendations regarding change disposition. Because of the possible involvement of multiple participants these reviews are coordinated and expedited. 
Proposed changes are reviewed to ensure that the change is desirable, valid, and can be accomplished. Reviews for technical, schedule, and cost impact are performed by personnel experienced and actively cognizant of the subject matter being reviewed. These reviews are performed to:

- Ensure that the change does not duplicate other changes that may be in the change control process

- Determine the validity of the change

- Identify and disposition impacts to other in-process changes

- Identify all affected products and associated documentation

- Determine the appropriate acceptance criteria

- Identify the impact to other participants, tasks, and products whether or not identified with the original change proposal

- Determine the impact on the technical, schedule, and cost baselines and other documents

- Ensure that the change proposal contains sufficient information to facilitate the management review and disposition

- Ensure that the change is consistent with mission objectives.

\subsubsection{Management Review and Disposition Change Proposal}

Management is actively involved with the change reviews to ensure the impacts on their tasks and products are known and all considerations are addressed. Management is informed so that when conflicts exist among participants and issues are escalated, the decisions are not significantly delayed.

Management reviews change proposals to verify that adequate technical reviews have been performed, the change package is complete and ready for implementation, and that any required external approvals are obtained before implementation, and to select and approve the change disposition. In addition, the review should determine:

- Is the change necessary?

- Do the benefits of the change warrant the-technical,-schedule,-.and cost impacts resulting from the implementation of the change?

- Are adequate resources available?

- Should management approval be based on criteria other than the above or the criteria used for technical review? 
- When, how, and under what conditions will the change be implemented and who will be responsible for implementation?

Management dispositions the proposed change (e.g., approves, disapproves) and the necessary implementation details. Some changes may be dispositioned as disapproved or for delayed implementation, conditional implementation, etc. For directed changes the disposition can include feedback regarding impacts and needs to the entity that directed the change.

\subsubsection{Coordinate Implementation}

An implementation plan that includes implementation prerequisites, conditions, and a schedule of actions to be completed by the impacted participants is required. Responsibility for overall implementation, as well as responsibilities of impacted participants, is required. Impacted participants track their actions for closure based on the implementation plan. Impacted participants provide the closure status to the CCAs. Impacts on the implementation schedule are assessed for impact to the change and the change implementation. The change itself may need to be reevaluated and may require change due to unforeseen impacts. If this occurs, then the additional change must be treated as a new change and undergo the reviews and processes appropriate to its impacts.

The level of planning and form that the implementation plans take depends on the importance, complexity, and type of change. Some steps for implementing changes have been built into related procedures and do not require separate planning (Paragraph 6.3). Change implementation plan requirements will be evaluated based on these criteria and specific direction provided in change control procedures. Implementation planning will address changes to impacted products and documents (e.g., operating and maintenance procedures, training, etc.).

\subsubsection{Issue Technical, Schedule, and Cost Changes}

Changes are issued in a prioritized manner to support implementation of the change. Issuance of technical changes follow the requirements hierarchy (e.g., a Safety Analysis Report is changed before the implementing design, operations, or maintenance documents). Technical, schedule, and cost changes are issued using the change control processes listed in Paragraph 6.3, above.

\subsubsection{Authorize Work}

Implementation of an approved change to an SSC will be accomplished via work authorizations in accordance with WHC-CM-1-8. Other implementation processes will be used depending on the life cycle phase.

\subsubsection{Validate/As Built Change}

When completed all changes are reviewed, inspected, and (if required) tested to determine if the change meets its post-implementation acceptance criteria. Engineering changes that, for some reason, will not be work-completed will have completed portions incorporated in engineering documents by an ECN. Impacted operating and maintenance documents will be revised to incorporate related change information. 


\subsubsection{Update Change Status}

Closure of all changes is required. If closure of the change or part of the change does not take place, further change processing is required to cancel, revise, or supersede the change so that actual implementation and closure status is reflected. If any portion of the change request has been implemented, the change request cannot be canceled. The responsible participants determine the content of the change revision and whether a new change must be processed.

\subsection{CHANGE CONTROL TRACKING}

The Integrated Project Information Management System (IPIMS) is used to provide change information and tracking. This information is available to all participants and provides additional integration through the sharing of change information. All CCAs have access to the IPIMS. The IPIMS provides status of change requests, ECNs, and schedules.

The current status of released technical and engineering changes is tracked and made available by the organizations and at the locations listed in Table 2 .

Table 2. Change Status Locations.

\begin{tabular}{||l|c|c||}
\hline \multicolumn{1}{|c|}{ DOCUMENT AND CHANGE TYPE } & ORGANIZATION & LOCATION \\
\hline $\begin{array}{l}\text { Engineering \& other Technica! Documents - } \\
\text { Engineering Change Notice (ECNs) }\end{array}$ & $\begin{array}{c}\text { Document Control Services } \\
\text { (DCS) }\end{array}$ & $\begin{array}{c}\text { See HLAN, Hanford } \\
\text { Info for closest DCS } \\
\text { Location }\end{array}$ \\
\hline $\begin{array}{l}\text { TWRS Operating Procedures (Except Characterization) } \\
\text { TWRS Administrative Procedures (Except Characterization) }\end{array}$ & $\begin{array}{c}\text { Tank Farm Transition Projects } \\
\text { Procedures }\end{array}$ & $\begin{array}{c}\text { *** } \\
2750 \text { E/D295/200E } \\
373-4802\end{array}$ \\
\hline TWRS Maintenance Documents (except Characterization) & $\begin{array}{c}\text { Tank Farm Transition Projects } \\
\text { Maintenance Programs }\end{array}$ & $\begin{array}{c}\text { ** } \\
2750 E / D 200 / 200 E \\
373-2270\end{array}$ \\
\hline $\begin{array}{l}\text { TWRS Characterization Operations and Maintenance } \\
\text { Documents (except Analytical Lab) }\end{array}$ & $\begin{array}{c}\text { TWRS Characterization Project } \\
\text { Production Control/ } \\
\text { Maintenance/Material } \\
\text { Readiness }\end{array}$ & $\begin{array}{c}2704 \mathrm{HV} / \mathrm{B} 135 / 200 \mathrm{E} \\
376-2615\end{array}$ \\
\hline $\begin{array}{l}\text { Analytical Lab Administrative, Operating, and Maintenance } \\
\text { Documents - PCAs and MPRs }\end{array}$ & $\begin{array}{c}\text { TWRS Characterization Project } \\
\text { Program Mgmt \& Integration }\end{array}$ & $\begin{array}{c}\text { MO291/A159/200W } \\
373-3076\end{array}$ \\
\hline
\end{tabular}




\subsection{CONFIGURATION STATUS ACCOUNTING}

Configuration status accounting is the processing and recording of information (e.g., engineering documents, database content) and changes to the approved information to maintain a continuous record of the selected baseline. Pending changes are tracked for visibility of pending actions. Status accounting provides accurate and timely information about the baseline to management, CCAs, schedulers, and others to manage the work effectively.

Status accounting information is obtained from various sources depending on the information being tracked. Information sources are identified in Table 1 for document status and Table 2 for change status. Other configuration management status information is available from the MEL and SEL (see Paragraph 2.6 of this CMPP). 
WHC-SD-WM-CM-013

Rev 0

This page intentionally left blank. 


\subsection{CONFIGURATION MANAGEMENT PROGRAM ASSESSMENTS}

The assessments element measures the configuration management program effectiveness in establishing and maintaining the basic configuration management relationships. Assessments assist in defining the needs of the configuration management program and evaluating the accuracy of the design requirements, product configuration, and product information. Where possible, other forms of assessments, audits, and findings will be used to minimize the need for separate configuration management assessments.

\subsection{PROGRAMMATIC ASSESSMENTS}

Programmatic assessments evaluate the adequacy of the TWRS configuration management program and procedures. Weaknesses within the program are captured in a WHC-SD-WM-CM-007, which identifies the deficiency and tracks the resolution. In addition, the compliance matrix identifies areas within the configuration management program that, although not considered weaknesses, are being reviewed for potential enhancements within the configuration management program.

\subsubsection{Initial Assessments}

During the planning for the development of the TWRS configuration management program, initial assessments are conducted to determine the strengths and weaknesses of existing programs and procedures to determine where upgrade actions and resource expenditures are necessary.

Existing assessments generated by audits, safety concerns, evaluations, and oversight reviews have been listed in the TWRS Configuration Management Compliance Matrix, and will be the areas that will be resolved as the first priority. New or supplemental assessments are performed to update information from previous assessments where necessary.

\subsubsection{Post-implementation Assessments}

Assessments are performed for each configuration management element to determine if the upgraded programs and procedures address identified weaknesses, are effective in accomplishing the configuration management functions, and are workable. After each system design basis document is developed by the design reconstitution program, a field validation is performed to ensure the accuracy among the requirements, physical configuration, and product information.

\subsubsection{Periodic Assessments}

Following implementation of the configuration management program and the appropriate adjunct programs, assessments are performed periodically-to-measure the overall configuration management program effectiveness and to determine if the degree of control is adequate and appropriate. The results of these assessments establish the basis for improvements or corrective action to the configuration management plan. 


\subsubsection{Vendor and Contractor Assessments}

Assessments of vendor and contractor configuration management program, procedures, or practices will be performed to ensure that provided services (products, designs, data, documents, construction, modifications, and tests) are adequately documented and controlled.

\subsubsection{Technical Reviews, Audits and Assessments}

Technical reviews, audits, and assessments evaluate the integrated development and evolution of the technical baseline. All reviews, audits, and assessments will ensure the proper development, establishment, control, and verification of the technical baseline. These will be used to verify conformance with system and design requirements or specifications.

TWRS engineering documentation and product information is subject to design verification in accordance with approved procedures and WHC-CM-6-1, EP-4.1, "Design Verification Requirements." These design reviews and verifications are integrated with other elements of project management (e.g., construction, operations, maintenance, safety, reliability, training, logistics support, etc.) to ensure the technical adequacy of the design and the conformance of the design with the technical baseline requirements. Deficiencies and/or discrepancies disclosed by the design review are resolved and documented. Design review status reports are prepared and distributed to participating contractors as required through DCS.

Specific reviews are defined by WHC-SD-WM-SEMP-002 to support the development and approval of the technical baseline as it evolves. These reviews and the respective technical baseline are listed in Table 3.

Table 3. Technical Baseline Design Reviews

\begin{tabular}{||l|l||}
\hline \multicolumn{1}{|c|}{ Review } & \multicolumn{1}{c|}{ Technical Baseline } \\
\hline System Requirements Review (SRR) & Functional Requirements Baseline \\
\hline Technical Requirements Review (TRR) & Technical Requirements Baseline \\
\hline Design Requirements Review (DRR) & Design Requirements Baseline \\
\hline System Design Review (SDR) & Design Configuration Baseline \\
\hline Preliminary Design Review (PDR) & Design Configuration Baseline (phase 2) \\
\hline Definitive Design Review (DDR) & Design Configuration Baseline (phase 3) \\
\hline Operational Readiness Review (ORR) & As-Built Baseline and Operational Baseline \\
\hline Decontamination and Decommissioning Review (D\&DR) & Decontamination and Decommissioning Baseline \\
\hline Mission Completion Review (MCR) & Decontamination and Decommissioning Baseline \\
\hline
\end{tabular}

\subsection{FUNCTIONAL CONFIGURATION ASSESSMENTS}

Functional configuration assessments are conducted for new products and modifications. Tests confirm the functional characteristics that satisfy the required functions. Similar tests are performed for the maintenance program as identified in Paragraph 8.5. Procurement acceptance and pre-operational and operational testing requirements are documented in test and evaluation plans. 


\subsection{PHYSICAL CONFIGURATION ASSESSMENTS}

Physical verification is performed using procedures developed for turnover and maintenance activities. Other physical verification is performed through as-built activities to ensure any differences between "as designed" and "as constructed" configuration are documented and dispositioned to consistency among the requirements, physical configuration, and product information.

Physical walkdowns are part of the initial, post implementation, and periodic assessments in accordance with WHC-SD-WM-WP-072, "Engineering Drawing Field Verification Program." During walkdowns, checks are made to establish the existence and accuracy of nameplates and nameplate data.

- The corrective actions include additional walkdowns to characterize the problem and to determine the extent of the problem.

- The corrective actions include evaluations to determine whether the physical configuration or the documentation should be changed.

- Discrepancies in nameplate information are corrected using the Tank Farm procedure 6-TF-100, "Maintenance Procedure (Waste Tank Labeling Procedure)."

\subsection{PRODUCT PERFORMANCE MONITORING}

Products that require the monitoring of performance are tested and evaluated periodically to determine if requirements are met. Information is collected and trended to identify aging degradation. Selected products require testing on a scheduled periodic basis to determine if the equipment still meets its design requirements.

- Monitoring addresses surveillance actions, periodic in-service inspections and tests, and other monitoring of SSCs to ensure safe and reliable operation of the product.

- Monitoring includes measurements to collect and trend data to actual aging degradation of equipment, as determined by the MCA program.

\subsection{POST-MODIFICATION TESTING}

The products are tested after modification to determine if the modified equipment still meets its design requirements before being turned over for service. If a modified product fails to meet its requirements, a technical review-and follow-up actions -will be completed before turnover for operations. Testing will be planned, documented, and controlled in accordance with WHC-CM-6-1, EP-4.2, "Testing Requirements." 
WHC-SD-WM-CM-013

Rev 0

This page intentionally left blank. 


\subsection{REFERENCES}

10 CFR 830.120, "Quality Assurance Requirements."

DOE 4700.1, "Project Management System."

DOE/RL-93-0106, "Tank Waste Remediation System, Program Management System

Description," Annex 4, "Configuration Management Policy."

DOE-STD-1073-93, "Guide for Operational Configuration Management Program."

Hanford Site A/E Standards, General Standards,

GG-DWG-01, Preparation and Control Requirements for Engineering Drawings.

GG-DWG-02, Autocad Discipline Layering Conventions.

GG-DWG-03, Drawing Index Numbering System.

GG-DWG-04, Parts List/Bill of Material.

GG-DWG-05, Guide for Historical Drawing Numbers.

Hanford Strategic Plan.

RLID 5000.1, "Baseline Execution and Management Process."

WHC-CM-1-5, Standard Operating Practices.

Section 1.2, "Startup and Restart of Facilities."

Section 7.3, "Identifying and Resolving Unreviewed Safety Questions."

WHC-CM-1-8, Work Management.

WHC-CM-2-5, Management Control System.

2.3, "Baseline Management."

4.1, "Change Control."

WHC-CM-3-5, Document Control and Records Management Manual.

Section 4, "Records Inventory and Disposition Schedules."

Section 12.7, "Approval of Environmental, Safety and Quality Affecting Documents."

WHC-CM-3-6, Uniform Publications System.

WHC-CM-3-10, Software Practices.

WHC-CM-4-46, Safety Analysis Manual.

WHC-CM-5-4, Laboratories Administration.

Section 3.9, "Laboratory Procedures." 
WHC-CM-6-1, Standard Engineering Practices.

EP-1.1, "Engineering Document Identification Requirements."

EP-1.2, "Engineering Specifications Requirements."

EP-1.3, "Engineering Drawing Requirements."

EP-1.5, "Interface Control Requirements."

EP-1.6, "Engineering Data Transmittal Requirements."

EP-1.7, "Engineering Document Approval and Release Requirements."

EP-1.12, "Supporting Document Requirements."

EP-2.2, "Engineering Document Change Control Requirements."

EP-3.3, "Vendor Information Requirements."

EP-4.1, "Design Verification Requirements."

EP-4.2, "Testing Requirements."

WHC-CM-6-2, Project Management, PM-14, "Project Baseline Management and Change Control."

WHC-IP-0842, Waste Tanks Project Administration Manual.

Volume II, Section 4.16.1, "Operating Document Control."

Volume V, Section 5.1, "Maintenance Document Control."

WHC-IP-1026, Engineering Practices Guidelines.

WHC-IP-1117, Hanford Site Systems Engineering Manual, Part III,

"Hanford Site Technical Baseline Database Change Request Preparation and Submittal."

WHC-SD-GN-CM-2001, Configuration Management Program Plan for Hanford Site Systems

Engineering."

WHC-SD-WM-CM-005, "List of Structures and Systems for the Tank Farm \&

Evaporator Configuration Management Program."

WHC-SD-WM-CM-007, "Configuration Management Compliance Matrix for Waste Tank Farms and the 242-A Evaporator of Tank Waste Remediation Systems."

WHC-SD-WM-CM-009, "Design Reconstitution Program Plan for Waste Tank Farms and Evaporator of Tank Waste Remediation System."

WHC-SD-WM-CM-011, "Hanford Site Waste Tank Farm Facilities Design Reconstitution Plan."

WHC-SD-WM-CM-014, "Tank Waste Remediation System Configuration Management Program Implementation Plan."

WHC-SD-WM-SEMP-002, "Tank Waste Remediation System, Systems Engineering Management Plan."

WHC-SD-WM-SRID-001, "High Level Waste Storage Tank Farms/242A Evaporator Standards/ Requirements Identification Document."

WHC-SD-WM-WP-072, "Engineering Drawing Field Verification Program."

6-TF-100, "Maintenance Procedure (Waste Tank Labeling Procedure)." 


\subsection{BIBLIOGRAPHY}

Electronic Industries Association EIA/IS-649, "Report for the Twenty-Ninth Annual Engineering and Technical Management Workshop," Sept. 18-22, 1995.

Electronic Industries Association EIA/IS-649, "National Consensus Standard for Configuration Management."

DOE 5480.31, "Startup and Restart of Nuclear Facilities."

DOE-RL, "Tank Waste Remediation System Program Management System Description," U.S. Department of Energy, Richland Operations Office, Richland, Washington, $\mathrm{b}$.

DOE/RL-95-31, "Systems Engineering Management Plan."

DOE-RL-92-59, "Tank Waste Remediation System Program Management Plan."

LA-UR-92-3196, "Safety Assessment for Proposed Pump Mining Operation to Mitigate Episodic Gas Releases in Tank 241-SY-101."

Nuclear Information and Records Management Association, Inc., PP02-1994, "Position Paper on Configuration Management."

WHC-CM-1, Company Policies and Charters.

WHC-CM-1-10, Safety Manual.

WHC-CM-1-11, Industrial Hygiene.

WHC-CM-2-1, Procurement Manual and Procedures.

WHC-CM-3-4, Information Release Administration.

WHC-CM-4-2, Quality Assurance Manual.

WHC-CM-4-29, Nuclear Criticality Safety Manual.

WHC-CM-6-3, Drafting Standards Manual.

WHC-CM-7-5, Environmental Compliance.

WHC-IP-0944, "Multi-Functional Waste Tank Facility Configuration Management."

WHC-SD-WM-CM-010, "Configuration Management Activities of Tank Farm \& Evaporator Facilities."

WHC-SD-WM-PLN-042, "Standardized Labeling Program for Tank Farms." 
WHC-SD-WM-CM-013

Rev 0

This page intentionally left blank. 


\subsection{GLOSSARY}

Aging Degradation - Aging effects that could impair the ability of structures, systems, and components to meet their design requirements.

As-Built - Documentation (for example, Piping and Instrument Diagrams, and database records) verified by physical inspection as depicting the actual physical configuration and verified as consistent with the design requirements.

As-Found - Information, often in the form of marked-up documents, that reflects the actual physical configuration and identifies any discrepancies with currently-approved facility documentation.

Authorization Basis - Those aspects of the facility design basis and operational requirements relied upon by DOE to authorize operation. These aspects are considered to be important to the safety of facility operations. The authorization basis is described in documents such as the facility Safety Analysis Report and other safety analyses; Hazard Classification Documents, the Technical Safety Requirements, DOE-issued safety evaluation reports, and facility-specific commitments made in order to comply with DOE Orders or policies. (Refer to DOE Order 5480.21, Unreviewed Safety Questions)

Baseline - A set of documented decisions that constitute an established reference position for control, status accounting, reviews, assessments, and changes. These decisions are delineated in selected technical and programmatic documents that are identified and controlled. Baselines are continually changing via an orderly control of changes as required by DOE-HQ, RL, and the configuration management programs, especially during the development phase. Therefore, the current baseline is always the previously approved baseline with all approved changes.

Basis - The basis is the full set of information used to establish a function, requirement, or baseline. The basis explains why a function, requirement, or baseline has been specified in a particular manner or as a particular value. The basis consists of the inputs, constraints (e.g., regulations), analysis, studies, and calculations. The basis includes that subset that relates to safety and the authorization basis.

Change - Any alteration or addition, temporary or permanent, to a product. Changes not within current design requirements involve design changes. For system, structure, or components, identical replacements are not changes.

Change Classification - A system of classifying changes for WHC programs and projects, based on the threshold criteria and approval requirements identified in this plan.

Change Control - A process that ensures all changes are properly identified, reviewed, approved, implemented, tested, and documented.

Change Control Administrator - The person responsible for processing proposed changes and maintaining the database that tracks change requests and change request status. 
Change Board - A board composed of technical and administrative representatives who review, approve, disapprove, or defer changes to a product (e.g., an approved cost, schedule, or technical baseline). These boards may be established by the WHC program, contractors, or individual projects.

Change Control Board (Programmatic) - A board composed of technical and administrative representatives from WHC and RL who review, approve, disapprove, or defer programmatic changes to an approved cost, schedule, or technical baseline. In addition, other site contractors, that support the WHC, may have their own change boards with well defined procedures and/or charters.

Change Control Board (Facility) - An optional board composed of technical and administrative representatives of the WHC program and project functional areas who evaluate and approve, disapprove, or defer proposed changes to an approved baseline configuration item. This board becomes mandatory when a proposed change from one project has an impact on another project or outside services.

Change Identification Number - The number assigned to each programmatic change request for tracking and reporting purposes.

Change Request - The document used to initiate changes to approved configuration information (e.g., program cost, schedule, and technical baselines) and uniquely identified by a change identification number. The change request is used to document change proposals that require dispositions by RL.

Computer Software - A set of computer source codes and/or commercial software, with the procedures, rules, and associated documentation and data pertaining to the operation of computer systems and includes user-provided instructions and data that implement pre-programmed algorithm control systems; computer codes and data that will reside in firmware; and, when specified by the cognizant manager, user-provided instructions and data used by commercial computer software such as spreadsheet and database packages.

Configuration - The functional and/or physical characteristics as delineated in technical documentation and achieved in a product (form, fit, and function).

Configuration Information - The data and documentation that defines, provides a basis for, or otherwise has an important relationship to a product and is controlled to maintain that relationship.

Configuration Item - A product that has been selected and for which the configuration and basis will be managed.

Configuration Item-Scope-Criteria - The set of requirements and guidance used to select products to be placed under configuration management. 
Configuration Management - An integrated management program used that establishes consistency among requirements, basis, functional configuration, physical configuration, and documentation, and maintains this consistency throughout the life of the product as changes occur.

Design Basis - The design basis is the full set of information used to establish a design. The design basis explains why a design requirement has been specified in a particular manner or as a particular value. The design basis consists of the design inputs, design constraints, design analysis, and calculations. It includes topical areas such as seismic qualification, fire protection, and safe shutdown. The design basis encompasses consideration of factors such as availability, efficiency, costs, and maintainability, and that subset that relates to safety and the authorization basis.

Design Reconstitution - An adjunct program to the configuration management program that accomplishes the one-time effort of identifying, retrieving, extracting, evaluating, verifying, validating, and regenerating missing critical design requirements and basis. Design reconstitution encompasses the following functions: developing associated program plans and procedures; identifying and retrieving design information from identified source documents; evaluating, verifying, and validating the design information; resolving discrepancies; regenerating missing critical design information; and preparing and issuing Design Information Summaries.

Design Requirements - Those requirements reflected in design output documents (such as drawings and specifications) that define the functions, capabilities, capacities, physical sizes and dimensions, limits and setpoints, etc., specified by design engineering for a structure, system, or component. The design requirements provide the results of the design process.

Design Review - An evaluation of structure, system, and component designs to ensure that requirements and considerations (both normal and emergency) of electrical, mechanical, thermal, hydraulic, safety, producibility, reliability, maintainability, quality, inspectability, interfaces, engineering standards, design, and fabrication practices are met for the intended application.

Design Verification - The process of reviewing, testing, checking, and/or otherwise determining and documenting whether a design conforms to specified requirements and is adequate for its intended application.

Document Control - A process that stores and controls, tracks status (especially during revisions), and retrieves documents.

Emergency Change - A change that requires approval to initiate work to correct a hazardous safety condition or that may cause work stoppage.

Engineering Change Notice - A form used to document, approve, and control changes to engineering documents. 
Engineering Document - Any text-type or pictorial information that describes, defines, specifies, reports, or certifies activities, requirements, procedures, or results of engineering activities and contains engineering and technical information that communicates concepts, plans, descriptions, criteria, requirements, standards, and instructions.

Engineering Drawing - A document that depicts by means of graphics, pictorial, and/or textual presentations the form, fit, and function requirements of item(s).

Facility Documents - Those documents that support facility operations, as-built configuration information (drawings, valve lists, etc.), the facility procedures for activities (operations, maintenance, and testing), and facility operational records (completed tests, work requests, and radiation survey maps).

Field Validation - For the design reconstitution program, the process of providing reasonable assurance that design requirements are properly reflected in the physical configuration and in the associated facility documentation. Field validation tests the strength of the basic configuration management relationships among the design requirements, physical configuration, and facility documentation.

Formal Design Review - Design verification performed by a systematic overall critical review and evaluation of a design by a committee representing various disciplines.

Functional Configuration - The actual or represented dynamic states of systems, structures, or components.

Functional Design Criteria - A formal document, normally prepared for DOE-controlled projects, that provides a summary description of new or modified structure, system, or component.

NOTE: $\quad$ Functional Design Criteria completely documents minimum concepts and requirements to form a basis and to provide limitations governing design for a complete, safe, and operable facility adequate for its intended use.

Graded Approach - A process by which the level of analysis, documentation, and actions necessary to comply with a requirement are made commensurate with many considerations, including the relative importance to safety, safeguards, and security; the magnitude of any hazard involved; the life cycle stage of a facility; the programmatic mission of a facility; the particular characteristics of a facility; and any other relevant factor.

Life Extension - Actions specifically designed to reduce aging stresses or reduce the effects of aging stresses for facility potentially life-limiting components, as might be necessary to achieve the desired lifetime. 
Material Condition \& Aging Management - An adjunct program to the configuration management program that encompasses the functions of: developing associated program plans and procedures; screening components to determine those that are potentially life-limiting for the facility; evaluating, aging degradation mechanisms; estimating the facility remaining lifetime; evaluating feasibility of continued operations and extended operations; performing detailed material condition and aging analysis; and developing necessary life extension techniques to achieve the facility desired lifetime defined by DOE.

Operating Configuration - The combination of the dynamic states of systems, structures, or components within an operating facility (functional configuration) and the physical state of those SSCs (physical configuration).

Participant - An organization that is performing tasks in direct support of the TWRS mission. An organization to which the TWRS configuration management program is applicable or that provides support to the TWRS configuration management program.

Physical Configuration - The actual physical makeup, location, arrangement, and material condition of products.

Product - Any item produced and or utilized by TWRS including physical items (e.g., tank waste, procured goods), software, documents, data, or systems, structures, or components (equipment). Within this CMPP the term product is used to connote an item that will be placed under configuration management.

Project Review - A review of engineering design documents by WHC to ensure that the design meets the criteria established in the technical baseline documents.

Release - An activity that certifies by a stamp that the engineering document is the controlled version, approved for the intended use, entered in a tracking database, and retrievable.

Structure. System, or Component Grade - A measure of the importance of structures, systems, and components (SSCs) within the facility, based on the most important design requirements applicable to the SSC, that can be used to determine priorities and proper levels of attention and resource allocations. Examples of SSC grades and associated priorities are: (1) safety, (2) environmental, (3) mission, and (4) others.

Supporting Documents. An engineering text document that describes, defines, reports, or certifies activities, requirements, procedures, or results of engineering activities that support the WHC onsite missions. Other work may use the supporting document system of identification, review, release, and change control.

Systems Engineering - The systematic approach used by management and engineering to transform technical goals into an optimized, integrated, operational, and physical system that achieves the mission. The iterative technical and management process applied throughout the system life cycle that produces and maintains a well-defined and documented system technical baseline. 
Technical Baseline - The defined and approved physical/functional configuration (requirements and design description) of an SSC or computer software. This includes the scope of work that is developed based on the technical requirements. (see WHC-CM-2-5, section 2.3)

Turnover Requirements - Facility physical conditions that will be met and documentation that is provided before a facility is turned over.

Vendor Information - Any type of technical documentation/information submitted by a vendor as part of a procurement. 


\subsection{ACRONYMS}

The following is a list of acronyms used within this document. This list does not include acronyms that are used as part of a document identifier (e.g., WHC-SD-WM-CM-013).

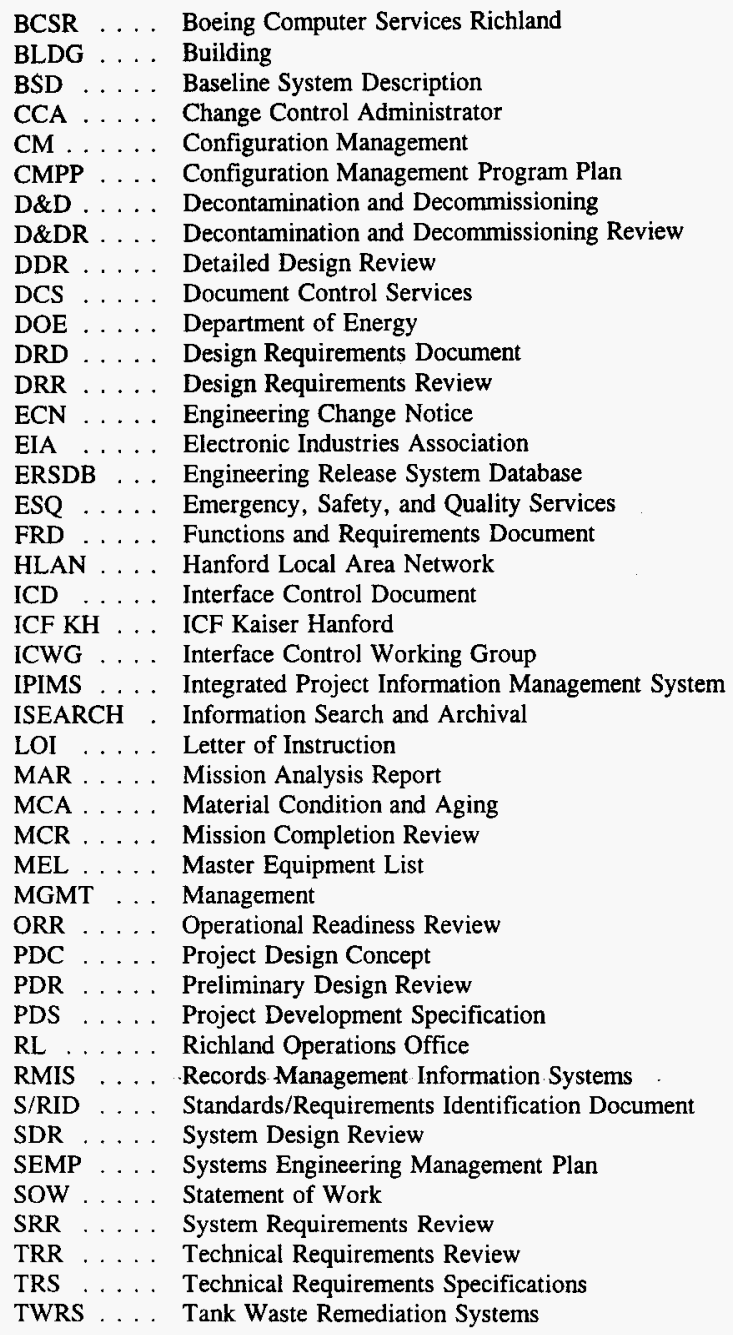


Rev 0

USQ .... Unreviewed Safety Question

WBS ..... Work Breakdown Structure

WHC .... Westinghouse Hanford Company 
WHC-SD-WM-CM-013

Rev 0

APPENDIX A

TWRS CONFIGURATION MANAGEMENT WORK BREAKDOWN STRUCTURE

Figure A-1. TWRS Configuration Management Work Breakdown Structure.

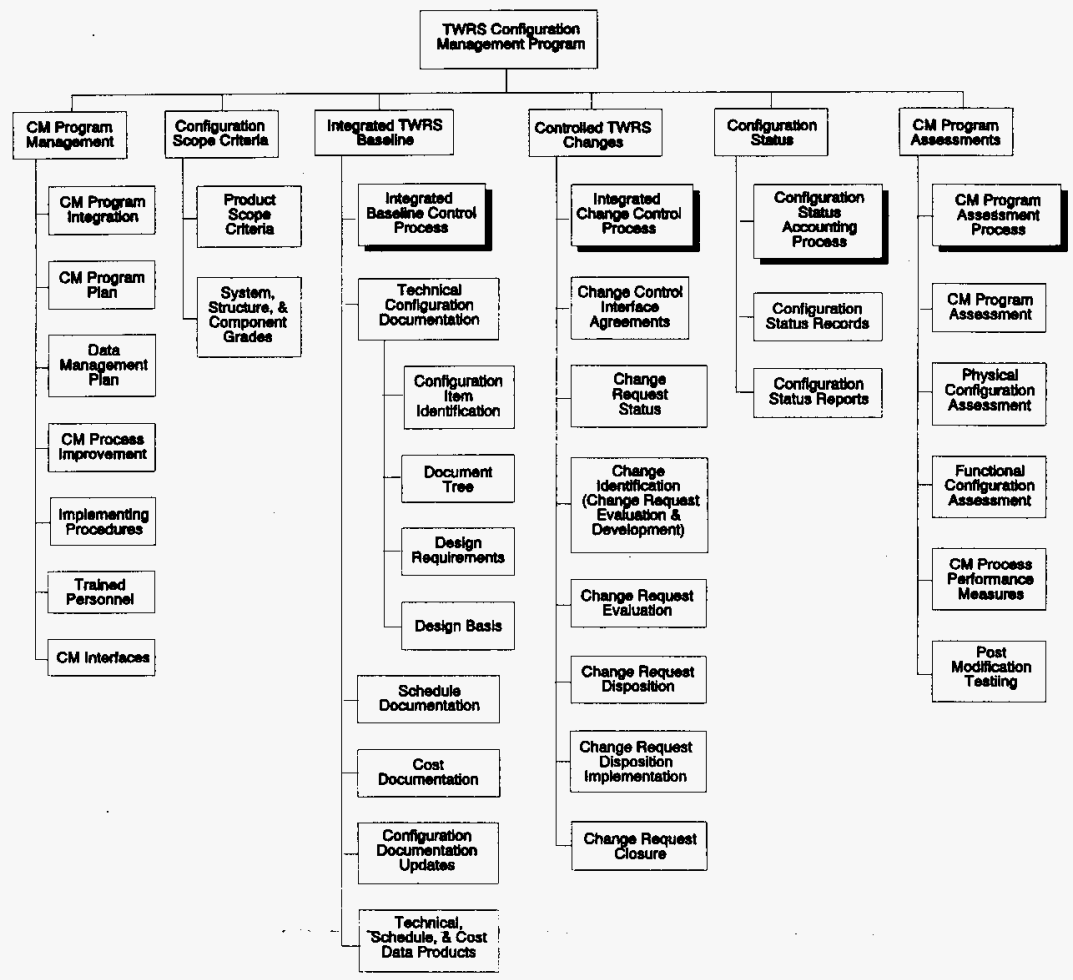


WHC-SD-WM-CM-013

Rev 0

This page intentionally left blank. 


\section{APPENDIX B}

\section{GRADED APPROACH}

The graded approach provides guidance on the process and methods that will be used to tailor the configuration management program and the adjunct programs of design reconstitution and material condition and aging management to the specific conditions and needs of the TWRS facilities. For this plan, the graded approach determines the level of detail required for documentation to adequately identify and control SSCs.

The graded approach is not being used to determine the selection of SSCs that are included in the TWRS configuration management program because all SSCs (as identified by WHC-SD-WM-CM-005, "List of Structures and Systems for the Tank Farm \& Evaporator Configuration Management Program") are within the scope of the configuration management program. The graded approach presented here determines the extent to which appropriate resources are applied to adequately document the SSC.

This graded approach does not eliminate or circumvent any of the elements or functions in the configuration management program. This approach does provide the process that identifies and integrates the existing methodologies of safety classification, operational requirements, and facility life-cycle phases for classifying the relative importance of SSCs and the necessary documentation to support SSC classification. The following grading criteria serves as guidance to determine the amount of documentation necessary to control and maintain the configuration.

\subsection{SSC SELECTION CRITERIA}

The SSC selection bases are:

$$
\begin{aligned}
& \text { - Safety class } \\
& \text { - Drawing category } \\
& \text { - SSC status. }
\end{aligned}
$$

\subsection{SAFETY CLASSIFICATION}

Safety classifications consider the consequences and impact to the environment, public, facility personnel, and D\&D activities due to the release of radiological and toxicological material into the surrounding environment. SSCs are classified according to their ability to prevent or mitigate the consequences of hazards and-design-requirement accidents in accerdance with the criteria established in WHC-CM-4-46, Safety Analysis Manual, as listed below. 


\section{APPENDIX B \\ GRADED APPROACH (cont.)}

\subsection{DRAWING CATEGORY}

SSCs are selected, categorized, and ranked based on their importance for safe operation and are depicted on the appropriate drawing category (essential, support, general, or construction) specified in WHC-CM-6-1, EP-1.3. Drawings that are identified as essential shall be re-evaluated if the SSC is used in limited operations in support of reduced facility mission. If an SSC was identified as essential to support facility limited operation and considered essential to support a reduced facility mission or deactivation, the drawing will remain essential.

\section{$1.3 \quad$ SSC STATUS}

SSCs are selected, categorized, and ranked based on their planned or scheduled physical disposition. The physical statuses are:

- Operational

- $\quad$ Full - SSCs that are required to support day-to-day operation of the facility and are operated at or near full.

- $\quad$ Limited - SSCs that are operated on an as-needed basis or are operated at a reduced capacity.

- Non-Operational

- Maintaining operational capability

- $\quad$ Not maintaining operational capability.

\subsection{DOCUMENTATION LEVELS}

1. Full Documentation - The set of documentation (e.g., design basis and requirements, drawings, specifications, operating and maintenance procedures) that specifies the function or performance of SSCs or depicts the physical arrangement of or environment within which the SSC performs its intended purpose.

2. Partial Documentation - The set of design basis and requirements documentation that defines an SSC that is necessary to support the safe operation and maintenance of a facility.

3. Minimum Documentation - The set of design basis and/or requirements documentation that defines a specific SSC that is necessary to support operations and maintenance of a facility. 


\section{APPENDIX B}

\section{GRADED APPROACH (cont.)}

\subsection{APPLICATION}

The configuration management graded approach is based on a fundamental requirement that all SSCs within a facility will be included in the configuration management program. The graded approach is used to identify the level of documentation that is required to define an SSC based on its importance to the facility, program, or project. Table B-1 summarizes the criteria that is used to determine the types and amount of documentation that is required to define and support each SSC that is in the configuration management program.

Table B-1. Graded Approach Criteria.

\begin{tabular}{|c|c|c|c|c|c|c|c|c|c|c|}
\hline \multirow{3}{*}{$\begin{array}{c}\text { LEVEL OF } \\
\text { DOCUMENTATION }\end{array}$} & \multicolumn{6}{|c|}{ CLASSIFICATION } & \multicolumn{4}{|c|}{ SSC STATUS } \\
\hline & \multicolumn{2}{|c|}{ SAFETY } & \multicolumn{4}{|c|}{ DRAWING } & \multicolumn{2}{|c|}{ OPERATIONAL } & \multicolumn{2}{|c|}{ NONOPERATIONAL } \\
\hline & $\begin{array}{l}\text { SC or } \\
\text { SS }\end{array}$ & $\begin{array}{l}\text { No } S C \\
\text { or SS }\end{array}$ & Essential & Support & General & Construction & Full & Limited & $\begin{array}{l}\text { Maintain } \\
\text { Operational } \\
\text { Capability }\end{array}$ & $\begin{array}{l}\text { Not Maintain } \\
\text { Operational } \\
\text { Capability }\end{array}$ \\
\hline Fulf & $\mathbf{R}$ & OP & $\mathbf{R}$ & OP & OP & $\mathbf{R}$ & $\mathbf{R}$ & OP & $\mathbf{R}$ & OP \\
\hline Partial & 8 & $O P$ & 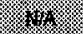 & $R$ & OP & 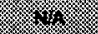 & 4 & $\mathbf{R}$ & 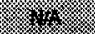 & OP \\
\hline Minimal & 4 & $\mathbf{R}$ & $x$ & s & $\mathbf{R}$ & 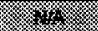 & 4 & 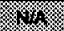 & w3. & $\mathbf{R}$ \\
\hline
\end{tabular}

SC $=$ Safety Class

SS = Safoty Significant

$R=$ Required

$\mathrm{OP}=$ Optional

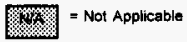

Table B-1 is used by starting with safety class and working down the flow path (Figure B-1) to determine, based on the available selections, what the highest level of documentation is required for the SSC under consideration. Once the highest level has been ascertained, Tables B-2 and B-3 are used to identify the types of documents that are required to support the facility and its SSCs. 


\section{APPENDIX B}

\section{GRADED APPROACH (cont.)}

Figure B-1. Graded Approach Criteria Flow Process.

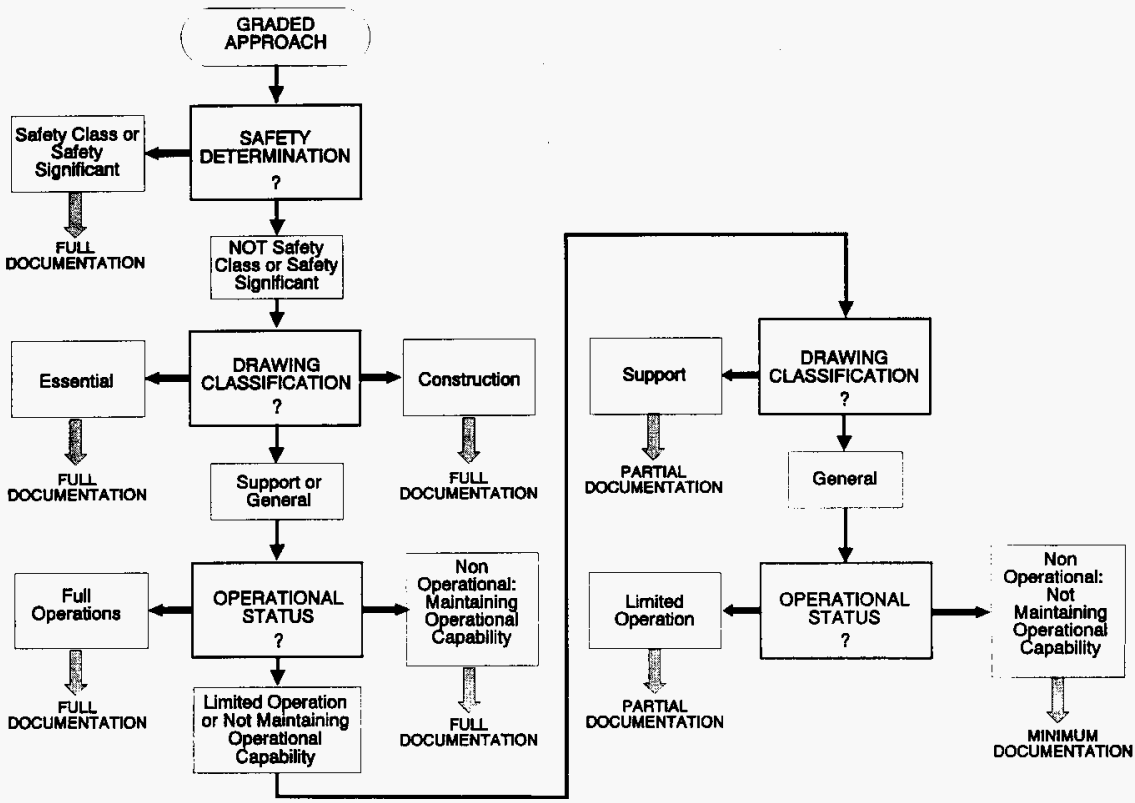

\subsection{DOCUMENTATION LEVEL RANKING}

Once the SSCs have been generally categorized, situations may occur where more than one SSC requires the same level of documentation and these SSCs appear to be of equal importance. A second set of criteria may be-required to rank SSCs within the same-documentation level (full, partial, or minimum). The following ranking guidance is provided to assist in this grading for appropriate documentation: 


\section{APPENDIX B}

\section{GRADED APPROACH (cont.)}

\section{First Ranking}

SSC STATUS

Note: Order of importance of this priority is independent of safety classification.

$1^{\text {st }} \quad$ Essential drawing

$2^{\text {nd }} \quad$ SSC is fully operational

$3^{\text {nd }}$ SSC is non-operational: Maintaining full operational capability

$4^{\text {th }} \quad$ SSC is operating on a limited basis

$5^{\text {th }} \quad$ Support drawing

$6^{\text {th }} \quad$ General drawing

$7^{\text {th }}$ SSC is non-operational: Not maintaining full operational capability

\section{Second Ranking}

\section{DOCUMENTATION CONDITION}

$1^{\text {st }} \quad$ Documentation is missing

$2^{\text {nd }}$ Documentation is incomplete and available information is inaccurate

$3^{\text {rd }}$ Documentation is complete and available information is inaccurate

$4^{\text {th }}$ Documentation is incomplete and available information is accurate

$5^{\text {th }}$ Documentation is complete and accurate

\section{Third Ranking}

\section{SSC REMAINING LIFE}
$1^{\text {st }} \quad$ Greater than 10 years
$2^{\text {nd }} \quad$ Between 5 and 10 years
$3^{\text {rd }} \quad$ Between 2 and 5 years
$4^{\text {th }} \quad$ Less than 2 years 


\section{APPENDIX B}

\section{GRADED APPROACH (cont.)}

Table B-2. Recommended Minimum SSC Design Basis Documentation According to Level.

\begin{tabular}{|c|c|c|c|}
\hline \multirow[b]{2}{*}{ DESIGN BASIS DOCUMENT } & \multicolumn{3}{|c|}{ LEVEL } \\
\hline & FULL & PARTIAL & MINIMUM \\
\hline Calculation and Analysis & - & & \\
\hline Computer Software Requirements & - & & \\
\hline Conceptual Design Report & - & - & \\
\hline Functional Design Criteria & - & & \\
\hline Functions and Requirements Document & - & - & \\
\hline Mission Definition Documents & $\bullet$ & & \\
\hline Safety Analysis Report (Preliminary/Final) & - & - & \\
\hline System Requirements Document & - & - & \\
\hline
\end{tabular}

Table B-3. Recommended Minimum SSC Requirements Documentation According to Level.

\begin{tabular}{|c|c|c|c|}
\hline \multirow[b]{2}{*}{ REQUIREMENT DOCUMENT } & \multicolumn{3}{|c|}{ LEVEL } \\
\hline & FULL & PARTIAL & MINIMUM \\
\hline Acceptance Testing & - & - & \\
\hline Computer Soffware Documentation & - & - & - \\
\hline Conceptual Design Report & - & - & \\
\hline Detailed Engineering Drawings & - & - & - \\
\hline Equipment Lists & - & - & \\
\hline Final Safety Analysis Report & - & - & \\
\hline Flow Diagrams (IEFDs AND P\&IDs) & - & - & \\
\hline Interface Control Document & - & $\bullet$ & - \\
\hline Operations and Maintenance Procedures & - & - & - \\
\hline Specifications & - & $\bullet$ & \\
\hline System Design Description & - & - & $\bullet$ \\
\hline Technical Safety Requirements & $\bullet$ & - & $\bullet$ \\
\hline Vendor Information & - & $\bullet$ & - \\
\hline Waste Tank Content Characterization Data & - & - & - \\
\hline
\end{tabular}




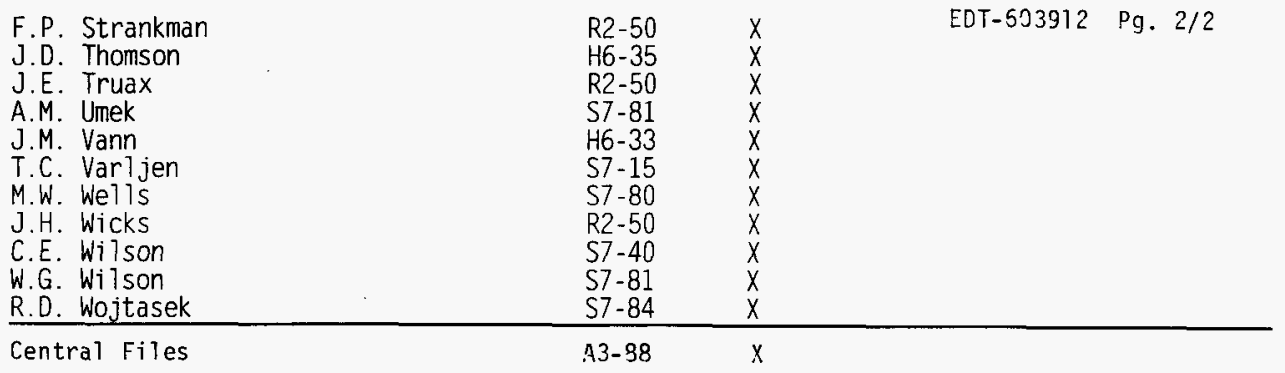




\section{DISTRIBUTION SHEET}

\begin{tabular}{|c|c|c|c|c|c|}
\hline \multirow{2}{*}{$\begin{array}{l}\text { To } \\
\text { Document Control Services }\end{array}$} & \multirow{2}{*}{\multicolumn{3}{|c|}{$\begin{array}{l}\text { From } \\
\text { Baseline Development \& } \\
\text { Management Systems }\end{array}$}} & \multicolumn{2}{|c|}{ Page 1 of 2} \\
\hline & & & & \multicolumn{2}{|c|}{ Date Apri] 12. 1996} \\
\hline \multirow{2}{*}{\multicolumn{4}{|c|}{$\begin{array}{l}\text { Project Title/work Order } \\
\text { Tank Waste Remediation Systems }\end{array}$}} & \multirow{2}{*}{\multicolumn{2}{|c|}{$\begin{array}{ll}\text { EDT No. } & 603912 \\
\text { ECN No. } & \text { N/A } \\
\end{array}$}} \\
\hline & & & & & \\
\hline Name & MSIN & $\begin{array}{l}\text { Text } \\
\text { With All } \\
\text { Attach. }\end{array}$ & $\begin{array}{l}\text { Text } \\
\text { Only }\end{array}$ & $\begin{array}{l}\text { Attach./ } \\
\text { Appendix } \\
\text { Only }\end{array}$ & $\begin{array}{l}\text { EDT/ECN } \\
\text { Only }\end{array}$ \\
\hline T.V. Anderson & H6-08 & $x$ & & & \\
\hline R.F. Bacon & S7 -85 & $x$ & & & \\
\hline P.A. Baynes & H6-33 & $x$ & & & \\
\hline J.G. Burton & $\$ 7-01$ & $x$ & & & \\
\hline S.J. Eberlein & $\mathrm{R} 2-12$ & $\ddot{x}$ & & & \\
\hline L.F. Ermold & $57-84$ & $x$ & & & \\
\hline H.P. Fox & R2-88 & $x$ & & & \\
\hline G.R. Franz & A2-34 & $x$ & & & \\
\hline K.A. Gasper & G3-21 & $x$ & & & \\
\hline J.E. Geary & S5-07 & $x$ & & & \\
\hline C.J. Geier & R2-36 & $x$ & & & \\
\hline J.W. Hagan & S7-81 & $x$ & & & \\
\hline E.R. Hamm & R2-40 & $x$ & & & \\
\hline A.G. Hoffman & $\mathrm{R} 2-40$ & $x$ & & & \\
\hline J.0. Honeyman & G3-21 & $X$ & & & \\
\hline J.A. Hubis & G6-64 & $x$ & & & \\
\hline R.D. Jensen & G3-21 & $x$ & & & \\
\hline T.J. Kelley & $\$ 7-21$ & $X$ & & & \\
\hline C.L. Kellie & $\mathrm{H} 6-33$ & $x$ & & & \\
\hline D.P. Kerwick & R2-88 & $x$ & & & \\
\hline J.A. Kimbrough & $57-04$ & $x$ & & & \\
\hline A.G. King & T6-03 & $x$ & & & \\
\hline E.J. Kosiancic & H5-61 & $x$ & & & \\
\hline K.K. Lachut & T6-03 & $x$ & & & \\
\hline R.E. Lerch & $57-85$ & $X$ & & & \\
\hline S.R. Long & $57-81$ & $X$ & & & \\
\hline G.A. Meyer & $52-48$ & $X$ & & & \\
\hline W.C. Miller & $A 2-34$ & $X$ & & & \\
\hline T.L. Moore & H6-11 & $x$ & & & \\
\hline T. Morton & S8-05 & $X$ & & & \\
\hline R.J. Murkowski & $\mathrm{H} 5-03$ & $x$ & & & \\
\hline M.A. Payne & $\$ 7-84$ & $X$ & & & \\
\hline L.G. Peck & H6-35 & $X$ & & & \\
\hline L.D. Pennington & $57-21$ & $x$ & & & \\
\hline R.S. Popielarczyk & $A 2-34$ & $x$ & & & \\
\hline R.W. Powell & G3-21 & $X$ & & & \\
\hline R.D. Raaz & $\mathrm{R} 2-40$ & $X$ & & & \\
\hline R.E. Raymond & $57-12$ & $X$ & & & \\
\hline D.P. Reber & T4-08 & $X$ & & & \\
\hline M.W. Rosenberry & $57-40$ & $X$ & & & \\
\hline W.E. Ross & $55-07$ & $X$ & & & \\
\hline V.L. Saladin & $k 6-51$ & $X$ & & & \\
\hline R.J. Shupe & R2-82 & $X$ & & & \\
\hline L.E. Simmons & R2-54 & $x$ & & & \\
\hline J.P. Sloughter & R2-54 & $X$ & & & \\
\hline
\end{tabular}

